\title{
Liebe und Ehe
}

Lehrgedichte von dem Stricker

Edited by

Wolfgang Wilfried Moelleken 
Liebe und Ehe 
From 1949 to 2004, UNC Press and the UNC Department of Germanic \& Slavic Languages and Literatures published the UNC Studies in the Germanic Languages and Literatures series. Monographs, anthologies, and critical editions in the series covered an array of topics including medieval and modern literature, theater, linguistics, philology, onomastics, and the history of ideas. Through the generous support of the National Endowment for the Humanities and the Andrew W. Mellon Foundation, books in the series have been reissued in new paperback and open access digital editions. For a complete list of books visit www.uncpress.org. 


\section{Liebe und Ehe \\ Lehrgedichte von dem Stricker}

EDITED BY WOLFGANG WILFRIED MOELLEKEN

UNC Studies in the Germanic Languages and Literatures

Number 65 
Copyright (C) 1970

This work is licensed under a Creative Commons CC BY-NC-ND license. To view a copy of the license, visit http://creativecommons. org/licenses.

Suggested citation: Moelleken, Wolfgang. Liebe und Ehe: Lehrgedichte von dem Stricker. Chapel Hill: University of North Carolina Press, 1970. DOI: https://doi.org/10.5149/9781469658018_Moelleken

Library of Congress Cataloging-in-Publication Data

Names: Moelleken, Wolfgang Wilfried, editor.

Title: Liebe und Ehe : Lehrgedichte von dem Stricker / edited by Wolfgang Wilfried Moelleken.

Other titles: University of North Carolina Studies in the Germanic Languages and Literatures; no. 65.

Description: Chapel Hill : University of North Carolina Press, [1970] Series: University of North Carolina Studies in the Germanic Languages and Literatures.

Identifiers: LCCN 72023045 | ISBN 978-1-4696-5800-1 (pbk: alk. paper) | ISBN 978-1-4696-5801-8 (ebook)

Classification: LCC PT1653.A4 M6 


Melita gewidmet 



\section{Vorwort}

Für die Abdrucksgenehmigung aus ihren Handschriften und Bereitstellung von Mikrofilmen bin ich den folgenden Bibliotheken zu Dank verpflichtet: Der Generaldirektion der Österreichischen Nationalbibliothek (Codices Vindob. 2705 und 2885), der Universitätsbibliothek Heidelberg (Cpg 34I), der Universitätsbibliothek München (Codex ms. 73I), dem Britischen Museum (Additional 24946) und dem Museum Ferdinandeum in Innsbruck (Codex 3200I). Herrn Professor Dr. A. Kracher, Universität Graz, verdanke ich einen Mikrofilm aus K. Zwierzinas NachlaB, dem ich die Überschriften aus dem verschollenen Codex Kalocsa Nr. I entnommen habe.

Die University of Virginia und die State University of New York haben die Vorarbeit zu meiner Strickerforschung gefördert. Den Mitgliedern des Forschungsausschusses der University of California in Davis bin ich besonders dankbar für ihre großzügige Unterstützung (intramural research grant No. I9900-5) der vorliegenden Arbeit.

Herrn Professor Dr. Siegfried Mews, dem Herausgeber der University of North Carolina Studies in the Germanic Languages and Literatures, danke ich für seine freundliche Hilfe und für verschiedene Anregungen bei der Fertigstellung des Manuskriptes. Herrn Professor Dr. Petrus Tax bin ich für viele Vorschläge, die ich meiner Arbeit einverleibt habe, zu großem Dank verpflichtet.

Wolfgang Wilfried Moelleken University of California

Davis, California 



\title{
Inhaltsverzeichnis
}

\author{
Einleitender Teil \\ I. Einführung . . . . . . . . . . . . . . . . . . . $\mathrm{xV}$ \\ II. Übersicht der Handschriften und Drucke . . . . . . . xxxiIt \\ III. Literaturverzeichnis . . . . . . . . . . . . . . . . $\mathrm{xxxIV}$
}

Modifizierter diplomatischer Text mit Varianten und Wort- und Sacherklärungen

I. Die Königin vom Mohrenland $\left(\begin{array}{lll}A & 39\end{array}\right)$. . . . . . . . . . 3

II. Das Wildpret $\left(A_{40}\right)$. . . . . . . . . . . . . . . . . 9

III. Die geliehenen Kleider $(A 56)$. . . . . . . . . . . . . 14

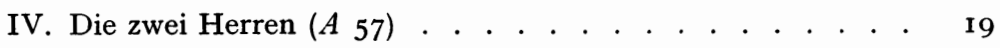

V. Der Kirchtag $\left(A 5^{8}\right)$. . . . . . . . . . . . . . . . . 23

VI. Der Krämer $\left(\begin{array}{l}A \\ 59\end{array}\right)$. . . . . . . . . . . . . . . . . . 26

VII. Das wilde Ross $(A$ 6r $)$. . . . . . . . . . . . . . . . . 33

VIII. Der Hort $(A 7 \mathrm{I})$. . . . . . . . . . . . . . . . . 38

IX. Der Gärtner $\left(\begin{array}{l}A 72 \\ 7\end{array}\right)$. . . . . . . . . . . . . . . . 4 I

X. Frauenleben und Pfaffenleben $(A 74)$. . . . . . . . . . 47

XI. Ehemanns Rat $(A 95)$. . . . . . . . . . . . . . . . 50

XII. Die Minnesänger $(A$ I55 $a$ und $b)$. . . . . . . . . . . . 57

XIII. Der einfältige Ritter $(A$ 204 $)$. . . . . . . . . . . . . . 69 

Einleitender Teil 



\section{Einführung}

Die vorliegende Auswahl macht es sich zur Aufgabe, den Themenkreis Liebe und Ehe in den Verserzählungen des mittelhochdeutschen Dichters Der Stricker erstmalig gesammelt in den Blickpunkt der Forschung zu rücken und einige seit langem schwer zugängliche Gedichte leichter verfügbar zu machen. Um die Auswahl auch für Übungszwecke brauchbar zu gestalten, wurden dem Apparat neben Varianten und textkritischen Bemerkungen auch Übersetzungen und Erläuterungen von schwierigen Satzkonstruktionen und Wörtern einverleibt.

Elf der hier abgedruckten Texte wurden im Jahre 1909 von Gustav Rosenhagen (Bib. A, I3) ${ }^{1}$ veröffentlicht (nach Handschrift $H$ mit Lesarten von $A$ ), das Gedicht $A$ I55 $a$ und $b$ (,die Minnesänger") erschien I 848 in von der Hagens Germania (nach Handschrift $A$, siehe Bib. A, 27) und nur $A$ 204, „Der einfältige Ritter,” ist auch neuerdings im Druck erschienen (vergleiche dazu die Úbersicht der Handschriften).

Sämtliche gebotenen Gedichte sind dem Codex Vindob. 2705 (Stricker $A$ ) der Österreichischen Nationalbibliothek zu Wien entnommen. Mit Ausnahme von neun Gedichten findet sich dort die gesamte, dem Stricker zugeschriebene Kleindichtung. Da diese Handschrift oft als ursprünglichste und verläßlichste bezeichnet wird, benützt man sie bei Strickerausgaben heute im allgemeinen als Leithandschrift (siehe Bib. A, 3 a und b, 4, 8, 24). Eine Beschreibung dieser und anderer Strickerhandschriften befindet sich bei Konrad Zwierzina (Bib. A, 30); Nachträge dazu bietet Heinrich Niewöhner (Bib. A, I9). Vor ihnen aber schon Hoffmann von Fallersleben (Verzeichnis der altdeutschen Handschriften der K. K. Hofbibliothek zu Wien, Leipzig, I840) und

1 Vollständige bibliographische Angaben im Literaturverzeichnis, S. xxxIv ff. 
Gustav Rosenhagen (Bib. A, I3). Eine weitere Beschreibung des Codex findet sich bei Hermann Menhardt (Bib. A, I7). Ute Schwab veröffentlichte 1959 eine tabellarische Übersicht über die Handschriften und Drucke der Strickeriana (Bib. A, 24).

Rosenhagen schreibt, da $\beta$ die Handschrift sich in braunem Lederbande befinde und auf dem Rücken in goldener Fraktur des I8. Jahrhunderts das Wort "Stricker" habe (Bib. A, I3, S. XXVIII). Die Handschrift ist aus dem I3. Jahrhundert und ist im bayrisch-österreichischen Dialekt verfaßt (Bib. A, 30, S. 279). Sie enthält I75 Pergamentblätter, 23,7-24 $\mathrm{cm}$ hoch und I6-I6, $3 \mathrm{~cm}$ breit. Jede Seite hat zwei Spalten und 46 Zeilen pro Spalte. Das Schriftfeld ist $12 \mathrm{~cm}$ breit und $18-19 \mathrm{~cm}$ lang. Die Liniierung ist meist verwischt, sie war mit Blei eingerissen. Die einzelnen Stücke haben keine Überschriften, beginnen aber mit Initialen und sind vom Schreiber numeriert. Absätze innerhalb der Gedichte kommen nicht vor, Initialen äußerst selten. Neben jedem Stück steht in roter Tinte in lateinischen Ziffern die Nummer. Vorne auf Folio I $v-2 v$ befindet sich ein Inhaltsverzeichnis, das nicht immer ganz genau mit dem Text übereinstimmt.

Die zweite Zeile eines Verspaares ist eingerückt, der Anfangsbuchstabe der ersten großgeschrieben. Meistens findet man langes $\Gamma$, gelegentlich aber auch $s$. Kursives $z$ findet sich oft vor $o$, aber nicht durchgehend. Gewöhnlich steht $v$ für $u$, aber auch oft das letztere. $o$ und $e$ stehen oft über einem Vokal, $w$ steht manchmal statt Vokal + $w$ oder $w+$ Vokal.

Für den Variantenapparat wurden alle verfügbaren Handschriften zu Rate gezogen:

Cpg 34I der Universitätsbibliothek Heidelberg (pg. fol. 2-spaltig, Stricker $H$ ) enthält alle hier aufgenommenen Lehrgedichte mit Ausnahme von $A$ I55 $a$ und $b$ sowie $A$ 204. $H$ ist aus dem I4. Jahrhundert und weist nach Zwierzina eine mitteldeutsch gefärbte Buchsprache, vielleicht aus Böhmen, auf. Gustav Rosenhagen (Bib. A, I3) besorgte 1909 im Rahmen der Deutschen Texte des Mittelalters eine Teilausgabe von $H$, in der die meisten Gedichte dieser Handschrift abgedruckt sind.

Codex Vindob. 2885 (Stricker $B$ ) der Österreichischen Nationalbibliothek in Wien (Pp. fol. 2-spaltig) enthält das Lehrgedicht $A$ I55 $a$ und $b$ sowie $A$ 204. Die Handschrift stammt aus Innsbruck, wo sie 1393 vom Schreiber Johannes Götschl verfertigt 
wurde. In $B$ befinden sich $A$ I55 $a$ und $b$ an getrennter Stelle (B 42 bzw. $B$ 6I).

$2^{\circ}$ Codex ms. 73I, Universitätsbibliothek München (pg. fol. 2-spaltig), ist vom I4. Jahrhundert und stammt aus Würzburg (Stricker $E$ ). Er enthält in $E 56$ und $E 57$ das Lehrgedicht von den Minnesängern ( $A$ I55 $a$ und $b$ ) und in $E 29$,den einfältigen Ritter" ( $A$ 204). Allerdings ist in $E$ ein Blattverlust von einem Blatt eingetreten, so da $B$ von $E{ }_{5} 6$ die Verse I-59 fehlen (nach Mitteilung von Oberregierungsbibliotheksrat Dr. G. Schott).

Strickerhandschrift $F$, Additional 24946 des Britischen Museums in London (Pp. fol. 2-spaltig) weist $A 204$ auf. Die Handschrift ist aus dem I5. Jahrhundert, die Sprache bayrischmittelfränkisch.

Codex 3200 I des Museums Ferdinandeum in Innsbruck (Pp. fol. 2-spaltig mit Bildern) ist vom Jahre I456 aus Tirol (Stricker $I)$. Er enthält in $I 39$ und $I 56$ „Die Minnesänger” bzw. „den einfältigen Ritter."

Die Lesarten von $B, I$ und $E$ stimmen in den meisten Fällen überein und legen ein enges Verhältnis dieser Handschriften nahe, wenigstens in den hier erfaßten Nummern. Konrad $Z$ wierzina deutet ebenfalls auf das nahe Verhältnis von $I$ und $B$ hin: „[I] enthält mit einigen Ausfällen dieselben Nrr. wie $B \mathrm{u}$. zw. mit verwandtem Text und, mit einer Abweichung, auch in gleicher Reihenfolge. Sie ist aber kaum direkte Abschrift von B" (Bib. A, 30, S. 28I). Und Hanns Fischer betont das äußerst nahe Verhältnis von $E$ und $B$ : „Am auffälligsten ist das häufige Zusammengehen von $E$ und $B$ - kleinere Unterschiede lassen sich aus ihrem zeitlichen Abstand erklären - gegenüber $A H^{\prime \prime}$ (Bib. A, 3 a, S. X).

Mit Ausnahme von $A$ I55 $a$ und $b$ sowie $A 204$ sind alle Gedichte der vorliegenden Ausgabe in der Handschrift Kalocsa I enthalten (Stricker $K$ ). Diese Handschrift ist jedoch während des zweiten Weltkrieges verlorengegangen (Mitteilung von Oberbibliothekar Kékesi János aus Kalocsa). Konrad Zwierzina teilt uns mit, da $\beta$ sie überall eine direkte Kopie von $H$ sei (Bib. A, 30, S. 28I), was von Heinz Mettke (Bib. A, 8, S. XIII) allerdings ,ein wenig" bezweifelt wird. Die Handschriftennummern von $K$ in der Übersicht der Handschriften und Drucke habe ich Konrad Zwierzinas Einteilung entnommen, von der mir Professor Dr. Alfred Kracher vom Germanischen Seminar der Universität 
Graz, wo Zwierzinas Nachlaß aufbewahrt wird, freundlicherweise einen Mikrofilm zugeschickt hat. Herbert Wolf schreibt (in „Das Märe vom Feldbauer," Zeitschrift für deutsche Philologie 87 [I968], S. 373, Anmerkung 4), daß $K$ jetzt in der Columbia University, New York, liegen soll. Die Handschriftenabteilung der Columbia University hat mir jedoch auf meine Anfrage hin mitgeteilt, daß dies nicht den Tatsachen entspricht.

„Textkritik und Editionskunst," schreibt Gabriele Schieb I966 (Bib. A, 23, S. 523), ,sind ungemein verantwortliche und grundlegende wissenschaftliche Aufgaben, zumal sie uns die oft als so selbstverständlich hingenommenen Fundamente erst vertrauenswürdig schaffen helfen, auf denen dann Sprachgeschichte und Literaturgeschichte ihre kühnen Gebäude errichten können. Wo immer man sich der Bedeutung dieser Wissenschaftszweige als Grundlagenforschung bewußt wurde, entflammte deshalb der Methodenstreit." Diese Worte beschreiben trefflich die Forschungslage der Strickerausgaben. Seit Bern. Jos. Docen I807 die ersten Strickergedichte zum Druck brachte (Bib. A, 6), hat man immer wieder mit der Frage gerungen, wie die Gedichte des Strickers der Öffentlichkeit übergeben werden sollten. Ältere Versuche beschränken sich auf Abdrucke, die aus einer Handschrift geschöpft sind (Bib. A, 6). Nach Karl Lachmann wurden die sogenannten normalisierten Ausgaben bevorzugt (Bib. A, 2, 3, 4, II, I4, I6, 24). Konrad Zwierzina, der viele Jahre damit beschäftigt war, eine Gesamtausgabe der Strickerschen Kleindichtung vorzubereiten (die leider auf Grund seines vorzeitigen Todes nie erschienen ist), veröffentlichte I926 (Bib. A, 30) fünf Strickerbeispiele im Carl von Krausschen Übungsbuch, deren Bearbeitung immer wieder als vorbildliches Beispiel wissenschaftlicher Arbeit bezeichnet wurde. Dabei bediente er sich eines streng diplomatischen Verfahrens, in dem er selbst solche Feinheiten wie die für den Inhalt sinnlosen Punkte am Ende der Zeile wiedergab, mit anderen Worten, einen genauen Abdruck der Handschrift erstrebte (den Unterschied zwischen kursivem $z$ und $r$ hat er jedoch nicht berücksichtigt, wohl aber den zwischen langem $\int$ und $s$ ). Besonders vorbildlich und ausführlich war dabei sein Variantenapparat, dessen Umfang deutlich machte, wie schwierig es ist, alle vorhandenen Textzeugen $z u$ Worte kommen $\mathrm{zu}$ lassen. Diese von $Z$ wierzina besorgten Texte, wohl das Diplomatischste, was wir vom Stricker im Druck haben, sind 
bisher auf wenig negative Kritik gestoßen. Hanns Fischer spricht (Bib. A, 9, S. 77) von Zwierzinas "Textproben und ihren unschätzbaren editorischen Beigaben," Ute Schwab preist (Bib. A, 25, S. 376) „die musterhaften bispel-Drucke Zwierzinas." Trotzdem (vielleicht, weil Zwierzina selbst einmal erklärte, er würde in einer eventuellen Gesamtausgabe den Text von allen „Unreinheiten" säubern) sind in der Folgezeit die Forscher dem Vorbild Lachmanns gefolgt und haben normalisierte Ausgaben einem diplomatischen Abdruck vorgezogen. In den Jahren I959/60 erschienen fast gleichzeitig drei Strickerausgaben, die sich der normalisierenden Methode bedienten (Bib. A, 3 a, 4, 24). Ute Schwab vertritt den Standpunkt, daß wegen der „vielfältig verflochtenen Überlieferung" nur ein weitgehend normalisierter Text in Frage käme. Solch eine Normalisierung wird ihrer Meinung nach erzielt, indem man "gesicherte Strickersche Spracheigentümlichkeiten" in den Text einschaltet (Bib. A, 25, S. 376). Von Hanns Fischer (Bib. A, 3 a, S. XI) wird ein „rein nach ästhetischen Gesichtspunkten wählender Eklektizismus" abgelehnt, weil dieser zu leicht in Gefahr gerät, „Zwitter ohne historische Realität hervorzubringen." Fischer versucht solchen subjektiven Textbearbeitungen aus dem Wege zu gehen, indem er in seinen Editionen (Bib. A, 3 a und b) einen normalisierten Text der Handschrift $A$ anstrebt.

Nur Mettke (Bib. A, 8) hat sich in den letzten Jahren um einen diplomatischen Text bemüht, dessen Variantenapparat jedoch leider nicht den Handschriften, sondern verschiedenen älteren Drucken Strickerscher Dichtung entnommen wurde.

Gegen normalisierte Texte sind beträchtliche Einwände erhoben worden. Man fragt sich, warum man einen Text eigentlich „reinigen” solle, der nie in solch einer gereinigten Form bestanden hat. Eine uneinheitliche Orthographie ist typisch für mittelalterliche Texte, und der Dichter der mittelhochdeutschen Blütezeit kannte keine standardisierte Schreibform. Gabriele Schieb ist folgender Meinung: „Grundsätzlich abgelehnt werden muß die leichtfertige Praxis, die lange in Mode war, Denkmälern, die man in ihrer ursprünglichen Gestalt dem deutschen Hochmittelalter zuwies, einfach das bequeme orthographisch standardisierte Sprachgewand eines normalisierten Mittelhochdeutsch überzuwerfen, auf das sich weite Kreise der Wissenschaft seit Lachmann, seinem Schöpfer, geeinigt hatten" (Bib. A, 23, S. 527). 
Man sollte weiterhin vorsichtig sein, Mehrverse aus anderen Handschriften in den Text einzubauen, denn diese können auf Interpolationen von späteren Bearbeitern beruhen. Gabriele Schieb betont (Bib. A, 23, S. 524), es komme „neben Abschriften mitunter auf Wunsch von Mäzenen oder durch die Nachfrage des Publikums zu neuen Redaktionen, die Sprache, Stil, Umfang, Aufbau oder Ähnliches antasten, und denen oft ein eigener Gebrauchswert zukommt." Die Handschriften $E, B$ und $I$ verdeutlichen solche Bedenken, weisen sie doch in $A 204$ von der Leithandschrift $A$ solch stark abweichende Fassungen auf, da $B$ eine Normalisierung oder ein nach ästhetischen Gesichtspunkten angewandtes Auswahlprinzip ohne Zweifel solche von Fischer erwähnten Zwitter zustande brächte.

Auf Grund der Strickerschen Überlieferung, die nun einmal vielfältig verflochten ist (wie Ute Schwab ganz richtig feststellt), muß man die Frage stellen, ob der Tatbestand nicht eine diplomatische Bearbeitung von $A$, der ursprünglichsten, verläßlichsten und ergiebigsten Handschrift der Strickeriana, unter Hinzuziehung sämtlicher Varianten, als empfehlenswerte Lösung nahelegt. Eine ähnliche Editionsform wurde auch von der Königlich Preußischen Akademie der Wissenschaften für die Ausgaben der Deutschen Texte des Mittelalters gewählt (Bib. A, I2), denen ich viele meiner Editionsprinzipien entnommen habe.

Im einzelnen galten die folgenden Richtlinien bei der Bearbeitung des Textes:

Graphische Eigenheiten der Handschrift werden beibehalten, doch bleiben Unterschiede zwischen kursivem $z$ und $r$, langem $\Gamma$ und $s$ unberücksichtigt. $u$ und $v, i$ und $j$, $w$ statt Vokal $+w$ oder $u$ sind geregelt. Bei der Auflösung von w erfolgt Kursivierung. Diakritische Zeichen wie hochgestelltes $o$ und $e$ werden ohne Hinweise im Apparat mit ihrem jeweiligen Grundvokal verbunden. Das Akzentzeichen (') und Punkte am Ende der Zeile werden nicht aufgenommen. Zirkumflex über dem Vokal wird im Text nicht gezeigt, aber im Apparat erwähnt. Zusammen- bzw. Getrenntschreibung erfolgt nach modernen Gesichtspunkten, in der Handschrift kann man oft nicht zwischen ihnen unterscheiden. Verderbte oder unleserliche Textstellen und Rasuren werden in Kursivschrift wiedergegeben und im Apparat kommentiert. Augenscheinliche Fehler in der Handschrift werden verbessert, kursiviert und im Apparat erklärt. Großschreibung 
erfolgt am Anfang des Gedichtes oder des Abschnittes, bei Namen nur, soweit diese im Gedicht auch Majuskel haben. Die zweite Zeile eines Verspaares wird nicht eingerückt wie in der Handschrift. Interpunktion erfolgt nach modernen Maßstäben. Die Absätze werden von mir angesetzt, oft in Übereinstimmung mit den Parallelhandschriften; $A$ weist in den vorliegenden Gedichten keine Absätze auf.

In den Lesarten wird das erste Wort der Textzeile der Deutlichkeit wegen großgeschrieben, auch wenn das dem handschriftlichen Gebrauch nicht entspricht. Orthographische Unterschiede habe ich im Apparat nicht aufgenommen, wohl aber wortliche, morphologische und solche der Wortstellung, wenn diese relevant erschienen. Die jüngeren Textzeugen weichen oft erheblich von der Leithandschrift ab. Daß sie zum Teil sehr Wesentliches bieten, beweisen die Lesarten von $B E I$ in $A$ I55, 165. Wo deshalb eine Lesart im Bereich des Möglichen lag, habe ich sie in den Apparat aufgenommen. Varianten der Erzählungen I - XI, die keinen Handschriftenverweis haben, stammen aus $H$. Die Orthographie richtet sich nach der Lautung der erstgenannten Handschrift. Im Falle von Varianten aus $A$ selbst gilt die für den Text maßgebliche Orthographie. Punkt steht im Apparat nach Abschluß der Variantenmitteilungen einer Textstelle, Strichpunkt zwischen den Mitteilungen. Textkritische Bemerkungen werden kursiviert, Erläuterungen, Kommentare und Übersetzungen in Anführungszeichen gesetzt. Abbreviaturen wie $\left({ }^{S}\right)$ und $(\sim)$ werden ohne Erklärung aufgelöst und im Text kursiviert. Mehrverse erscheinen im Apparat.

Nur Lehrgedichte von dem Stricker, die das Thema Liebe oder Ehe zum zentralen Anliegen haben, wurden für diese Ausgabe verwertet. Es muß jedoch betont werden, daß die sogenannten Ehestandsbîspel nicht zu diesem Themenkreis gehören, obwohl auch sie viele Schlüsse über das Verhalten in der Ehe ermöglichen. In den Ehestandsgedichten macht es sich der Dichter nicht zur Aufgabe, die Auffassung der Ehe zu erhellen, sondern hier geht es ihm um etwas anderes: etwa darum, die Prudentia in den Blickpunkt seines Publikums zu rücken (Bib. B, 2, I7) oder eine geistliche Moral zu verdeutlichen (Bib. B, I3-I6).

Der vorliegende Themenkreis „Liebe und Ehe” in der Strickerschen Dichtung ist bisher so gut wie undiskutiert geblieben, obwohl er literarhistorisch wertvolle Schlüsse erlauben würde. 
Der Stricker ist ein früher Vertreter der Nachklassik, und die ausgewählten Gedichte zeigen deshalb besonders gut die veränderte Haltung, die die nachhöfische Dichtergeneration diesem in der vorhergehenden höfischen Periode so eminenten Thema entgegenbringt. $\mathrm{Da} \beta$ der Stricker einer der ersten ist, der sich damit auseinandersetzt, überrascht nicht, wenn man sich seine Vielseitigkeit und seine für das Mittelalter ungewöhnliche Originalität vor Augen hält.

Um I2I5 bearbeitet er in seinem Karl dem Großen (Bib. A, I) das Rolandslied ${ }^{1}$ des Pfaffen Konrad neu für seine Zeit und schlägt damit eine wichtige literarische Brücke zwischen der vorund nachhöfischen Ära. Vierzig erhaltene Handschriften dieses im Mittelalter äußerst beliebten Epos zeugen außerdem für die gelungene Verbreitung des Chanson de Roland, ${ }^{2}$ dieser matière de France, auf deutschem und österreichischem Boden.

Im Daniel von dem Blühenden Tal, ${ }^{3}$ der wohl nach dem Karl entstanden ist, wie mehrere Anklänge an das Rolandslied vermuten lassen, stellt er uns die Artuswelt und die Ideale der ritterlich-höfischen Gesellschaft, die Hartmann von Aue und Wolfram von Eschenbach einige Jahre vor ihm so meisterhaft gepriesen hatten, noch einmal vor. Doch merkt man den Artusrittern des Strickers schon seine bürgerliche Betrachtungsweise an: die Tapferkeit, die den höfischen Artusritter auszeichnet, wird durch einen Zug der List ergänzt, ohne die seine Helden, trotz ihrer Tapferkeit, zugrunde gehen würden:

$\begin{array}{ll}\text { Daniel 7487: } & \text { Swer iht guoter liste kan, } \\ & \text { den solde wîp unde man } \\ & \text { gerne êren dester baz. } \\ & \text { ein man tuot mit listen daz, } \\ & \text { daz tûsent niht entæen, } \\ & \text { swie grôze kraft sie hæten. }\end{array}$

Die Minne, früher das zentrale Motiv des Artusepos, fehlt bei ihm fast ganz, weil er die Minnegesetze der vergangenen Generation nicht mehr anerkennt. Man wirft dem Stricker oft vor, da $B$ er diese nicht mehr versteht. Hanns Fischer (Bib. B, 6, S. 39) ist zum Beispiel folgender Meinung: „Damit kommen wir zu

1 hsg. Carl Wesle, Bonn, 1928.

2 hsg. Joseph Bédier, Paris, 1921, ${ }^{2}$ I 937.

${ }^{3}$ hsg. Gustav Rosenhagen, Breslau, 1894 . 
dem am schwersten wiegenden Mißverständnis unseres Dichters. Sein Held besteht zwar die gefährlichsten Abenteuer zur Rettung schöner Frauen, aber von Minne ist im ganzen Epos nicht die Rede." Gustav Rosenhagen (Bib. A, 21, S. I05) meint, daß dem Stricker für die „feine Auffassung der Minne” das Verständnis zwar fehle, daß dieser Mangel aber nur so zu erklären sei, da $\beta$,er sie nicht für eine notwendige Ingredienz des Rezeptes hielt. [...] Dem Stricker erscheint die Liebe als eine Torheit, als eine schädliche Leidenschaft, über die seine Helden erhaben sein müssen." Nicht Unwissen oder Verständnislosigkeit des Dichters, sondern bewußte Stellungnahme zur Minneauffassung läßt der Daniel erkennen. Unterstützt wird diese Behauptung im Epos selbst, wo der Stricker Stellung zum Thema Minne nimmt:

\begin{tabular}{|c|c|}
\hline Daniel I58I: & $\begin{array}{l}\text { Hie erzeigte frou Minne, } \\
\text { daz er vil starker sinne } \\
\text { in einem stæten muote hât, } \\
\text { den si des niht übergât, [,überredet”] } \\
\text { daz er diene nâch ir lône; } \\
\text { daz siu mit Salomône } \\
\text { harte wol erzeigen kan; } \\
\text { daz was der witzigeste man, } \\
\text { von dem ich ie gesagen hôrte, } \\
\text { unz daz si im zerstôrte } \\
\text { die wîsheit und die sinne. } \\
\text { daz selbe hât frou Minne } \\
\text { vil mangem werden man getân. } \\
\text { es endarf iuch niht wuncier hân, } \\
\text { daz si hie wart sigehaft. } \\
\text { an swen si leget ir kraft, } \\
\text { der muoz ir sîn undertân. }\end{array}$ \\
\hline
\end{tabular}

Diese dämonischen, verderblichen Kräfte der Minne veranschaulicht er am Beispiel des Zwerges Jurân, den die Minne zur Herrin von dem Trüeben Berge in den Tod treibt. Nachdem Daniel die Dame von diesem Zwerg befreit hat, bietet sich ihm die Möglichkeit, sie zu besitzen:

Daniel I762: wolder ir lîbes hân begert, als diu âventiure giht, si enhætes im verseit niht.

Doch im Bewußtsein der schädlichen Kräfte der Minne und 
seiner sich selbst gestellten Aufgabe, die Freude am Hof, die von außen her bedroht worden war, wiederherzustellen, macht er keinen Gebrauch von dieser Möglichkeit:

Daniel I779: er saz ûf unde reit.

daz was der frouwen harte leit.

Erst nach bestandenen Abenteuern und nach Wiederherstellung der Ordnung nimmt Daniel die ihm von König Artus als Lohn angebotene Königin von Clûse zur Ehefrau.

Im Pfaffen $A m \hat{\imath} \hat{s}^{\mathbf{1}}$ erzählt er in einer Reihe von Schwänken die Geschichte eines Geistlichen, der sich listig und seine Mitmenschen prellend durch die Welt schlägt. Diese Schwänke werden nicht nur durch die Einheit der Titelfigur zusammengehalten, sondern auch durch kompositorische Maßnahmen geschickt verbunden (siehe Bib. B, 7), so daß wir berechtigt sind, hier vom ersten Schwankzyklus in deutscher Sprache zu reden, der oft als Vorläufer des Schelmenromans und der Novelle bezeichnet wird. Auch übt er einen großen Einfluß auf spätere Schwanksammlungen wie Neidhart Fuchs, den Pfaffen vom Kalenberg, Markolf, Peter Leu und Till Eulenspiegel aus.

In seiner Kleindichtung erreicht der Stricker den Gipfel seiner Schöpferkraft. Seine bîspel, Schwänke, Anekdoten und seine didaktische Dichtung spiegeln seine Vertrautheit mit Bauern, Bürgern und Geistlichen, befassen sich aber auch, manchmal nicht sehr schmeichelhaft, mit dem Adelsstand. Er streift darin eine Vielfalt von menschlichen Gebieten und behandelt allgemeine Lebensweisheiten wie auch traditionelle Themen der Tugend- und Minnelehre. Besonders zahlreich sind die geistlichen bispel, die man zum Teil nicht von der reinen Verspredigt unterscheiden kann.

Der Stricker wird oft als Meister und Hauptvertreter des bîspels, ja, als sein Schöpfer par excellence bezeichnet. Das bîspel ist eine ,,selbständige epische Kurzform didaktischen oder satirischmoralischen Inhalts in mhd. Lit. nach Art der lat. $\rightarrow$ Exempla mit Nähe zur Fabel. [...] an e. kürzeres Einzelbild oder -geschehnis aus Menschen- oder Naturleben schließt sich e. Verallgemeinerung mit längerer Erläuterung e. moralischen Satzes an."2 Fehlt der

1 Evzählungen und Schwänke, hsg. Hans Lambel, Leipzig, I872.

2 Siehe Gero von Wilpert, Sachwörterbuch der Literatur, Stuttgart, ${ }^{3}$ I96I, S. 64 . 
erste Teil (das Einzelbild oder -geschehnis), neigt das bîspel zur reinen Didaxe (zur rede), beim Stricker oft zur Predigt, fehlt der zweite Teil (die Verallgemeinerung), haben wir einen Schwank, eine Anekdote, eine Versnovelle oder ein mare. ${ }^{1}$ Im Reallexikon versucht E. Neumann den Unterschied zwischen dem bispel und der Erzählung, dem mare, folgendermaßen zu beschreiben: „Die $\mathrm{B}$ [îspel] unterscheiden sich deutlich von den maren, bei denen die Erzählung die Hauptsache und die moralische Lehre nur locker angehängte Schlußbemerkung ist." 2 Man muß hinzufügen, daß auch ohne die Verallgemeinerung und Erläuterung eines moralischen Satzes bzw. einer moralischen Lehre, die beim Stricker fehlen kann (siehe Fischer, Bib. B, 6, S. 99-I25), eine Moral in der Geschichte enthalten sein kann, wenn auch nur implicite, ${ }^{3}$ wie auch die Lehre ohne epischen Teil unterhaltend sein kann. Außerdem kann der erste Teil dieses „kurzen Einzelbildes” länger als der zweite, die Verallgemeinerung, sein. In den vorliegenden bisspelen ist das Verhältnis vom ersten zum zweiten Teil in sechs Fällen ungefähr gleich (I, IV, V, VI, VIII, XIII), in zwei Fällen ist der erste Teil größer (III = 3:2, VII =4:I) und nur in drei Fällen ist der zweite Teil größer (II=I:5, IX=2:3, $\mathrm{X}=\mathrm{I}: 4$ ). In zwei Fällen (XI und XII) fehlt der erste Teil ganz.

Für den Titel dieser Ausgabe wurde die Bezeichnung „Lehrgedichte" und nicht bîspel gewählt, weil zwei der aufgenommenen Stücke (XI und XII) keine bîspel im eigentlichen Sinne sind, sondern reden, denen der epische Teil fehlt. „Lehrgedicht” umschließt jedoch die Gattung des bispels und der rede (siehe Gero von Wilpert, op. cit. S. 323 f. sowie Reallexikon, Band II, unter „Lehrhafte Dichtung," S. 3I-39).

Im Falle des geistlichen bîspels bezeichnet Ute Schwab den ersten Teil als das Gedeutete $(=\mathrm{A})$ und den zweiten Teil als Deutung $(=\mathrm{B}) .^{4}$ Die Frage, ob der erste in einem bestimmten

1 Karl-Heinz Schirmer entschließt sich für „Versnovelle” (Stil- und Motivuntersuchungen zur mittelhochdeutschen Versnovelle, Tübingen, 1969), Hanns Fischer gebraucht mare (Studien zur deutschen Märerdichtung, Tübingen, 1968).

${ }^{2}$ Zweite Auflage, hsg. Werner Kohlschmidt und Wolfgang Mohr, Band I, Berlin, 1958, S. 178 .

${ }^{3}$ Siehe Fischer, Bib. B, 6, S. 103, Anm. I : „natürlich haben auch die rein epischen Stücke lehrhaften Nebensinn."

4 Siehe ihre Vorbemerkungen im Kommentar von Bib. A, 24, S. 235-236. 
Verhältnis zum zweiten Teil steht oder ob zwischen der Geschichte und deren Auslegung ,überhaupt keine innerliche Verbindung" besteht, wird dahingehend beantwortet, daß die Tradition der geistlichen expositio den Stricker bei seiner Dichtung stark geleitet hat und daß es sehr enge Verbindungen zwischen den zwei Teilen gibt. Sowohl die moralische Lehre (die moralisatio), die oft eine Bekräftigung aus der Bibel enthält, als auch seine Erzähltechnik verraten seine Schulung in der Bibelinterpretation. Für die Verbindung von A und B wird eine Proprietät der Sache herangezogen (ein tertium comparationis), die in beiden Teilen einen Anhaltspunkt hat. Dabei geschieht die Verbindung oft implicite, ohne daß dabei dem mit solchen Proprietäten bekannten Publikum der tiefere Sinn entgangen wäre.

Man erkennt des Strickers exegetische Schulung nicht nur in den geistlichen bispelen, sondern auch in den weltlichen, wie die vorliegende Auswahl aus seiner Dichtung offenbart. Elf der hier abgedruckten Erzählungen haben einen Teil A (Gleichnis) und einen Teil B (Deutung), die mittels eines tertium comparationis, das sich mehrerer Proprietäten der Sache bedienen kann, verbunden werden. In allen hier vorliegenden Fällen folgt der Deutung, manchmal auch schon dem Gleichnis, die moralisatio. Im Reallexikon (S. I78) wird das geradezu als typisch für die Gattung des bîspels bezeichnet: „Im B[îspel] dagegen zielt bereits die Erzählung auf die darin versinnlichte und versinnbildlichte Lehre, und die erläuternde Ausdeutung nimmt das Erzählte (oft mit Rückgriff auf den Wortlaut der Geschichte) in die Lehre hinein, so daß Erzählung und Lehre aufeinander hingeordnet sind und ein einziges Lehrganzes bilden." So ist zum Beispiel in Editionsnummer I, der „Königin vom Mohrenland," die Geschichte der Königin, von der die minnenden Ritter sich abkehren, das Gleichnis. Indem sie die Ritter an ihrem Hof vernachlässigt und ihnen ihren Dank für ihre höfischen Bemühungen versagt, verursacht sie eine allgemeine Verschlechterung der Sitten, denn die Ritter wenden sich, in ihrer Tätigkeit mißachtet, von den höfischen Sitten und der Königin ab, um sich der schwarzen Heidenkönigin und ihren Frauen zuzuwenden. Teil B bringt dann die Deutung. Wie die Königin ihre Ritter und die höfische Gesellschaft gesellige Unterhaltung und freudige Stimmung einbüßt, so verliert die Welt ihre vröude, wenn sich die Menschen von der höfischen Lebensweise abwenden. Die 
Heidenkönigin und ihr schwarzer Hof bergen die zu betonende Proprietät der Sache: schwarz und Heide sind identisch mit dem Unchristlichen und der Sünde. Man beachte, daß die weißen Ritter, nachdem sie sich vom christlichen Glauben abgewandt haben, schwarz werden!

$$
\begin{aligned}
& \text { swen si uberwunden, } \\
& \text { daz er ir leben anegie, } \\
& \text { der wart swarz als sie. (I, 30-32) }
\end{aligned}
$$

Übertragen auf die Welt in Teil B besagt es, daß der Verlust der höfischen Sitten und die Abkehr von der hohen Minne mit dem Bösen und der Sünde verbunden ist.

Obwohl Minne und Ehe in den Gedichten des Strickers eine andere Bedeutung haben als bei den Vertretern der höfischen Zeit, fehlen die traditionellen Begriffe der Klassik, wie êre, hôchgemüete, hôhe minne, huote, triuwe und vor allem stete darin nicht. Einige Beispiele mögen den Unterschied erhellen.

In Editionsnummer I, der „Königin vom Mohrenland,” wird der Verlust von vröude und êre am Hofe der Königin beklagt, den Ritter und Damen zugleich verschuldeten, weil sie sich von der hohen Minne abwandten und der niederen Minne ergaben. Dieser Zerfall kam zustande, weil die Herrin die Gesetze der hohen Minne mißachtete, indem sie den Rittern gebührenden Dank für triuwe und state vorenthält:

$$
\begin{aligned}
& \text { „ist daz wir got und iu gestan, } \\
& \text { des sult ir uns geniezzen lan. } \\
& \text { welt ir uns niht danch sagen, } \\
& \text { damit meget ir uns verjagen } \\
& \text { und mugt uns gar verliesen." (I, 45-49) }
\end{aligned}
$$

Die Königin in A wird mit der Welt verglichen, der ein ähnliches Schicksal wie dieser widerfährt, weil schlechte Sitten darin überhand genommen haben, die die Ideale der hohen Minne zerstören und verschamte wîp, das heißt die niedere Minne, die Oberhand gewinnen lassen.

Do geschach der werlt ein solhe schade als der kuniginne geschach, diu ir riter sich vercheren sach. also chom ein tugentloser sit, da wart diu werlt vercheret mit, 
daz man verschamter wibe phlach.

swelhe riter bi den gern lach,

der wart zu hoher minne enwiht

und enahte uf die vrowen niht. (I, 84-92)

In Editionsnummer II, dem „Wiltpret,” erklärt der Dichter, daß der höfische minnare nur an den Damen Gefallen findet, die nicht wie veil wiltbrat leicht zu erjagen sind. Nach dem Schwierigkeitsgrad des Jagens schätzt der wahre Jäger den Wert seiner Beute ein!

swie schone ein veile wip si,

ir minne ist niht freude bi.

ezn wirt dehein veilliu brout

dem wisem manne nimmer trout,

si chumt den toren ze mazze

sam daz veil wiltbræt ze frazze.

(II, 27-32)

Während des langen Dienstes, den eine Dame vom werbenden Ritter verlangt, lernt dieser fuoge und bescheidenheit (57), vrumecheit (64), zuht und kunst (65). Wenn die Dame ihn dann schlieBlich mit ihrer hulde und ihrem gruoz (38) ehrt, ist ihm ein Leben voll vröude gewährt. Läßt sich eine Frau jedoch zu schnell erringen, wird sie mit Verachtung gestraft, denn sie enthält dem Ritter die vröude des Werbens vor, sie gleicht dem feilen Wiltpret, an dem sich nur der Vielfraß, nicht aber der wahre Weidmann erfreuen kann. Solch eine Frau muß die Leiden einer ehrlosen, verachteten Frau ertragen: nît und gittecheit (II9), sware und leit (120), schande (124) sind ihre Begleiter.

In den „zwei Herren” (Ed. Nr. IV) vergleicht der Stricker eine leicht einnehmbare Burg mit einer unbeständigen Frau. Beide verliert man so schnell, wie man sie gewonnen hat. Die feste Burg aber gleicht dem staten wîp (59), das die größte vröude spenden kann, wenn es dem Ritter nach harter Arbeit gelungen ist, „daz ir sin dienest angesiget.” (95)

Auch das bîspel vom „Krämer” (Ed. Nr. VI) exemplifiziert den Wert der state, dieses Mal die des Mannes. Der state Mann gleicht der goldenen Ware des ersten Krämers, die zwar teuer ist, aber ihren Wert behält, während die billige Ware des zweiten Krämers sich bei genauerer Untersuchung als Kupfer herausstellt, das mit goldener Farbe, deren Schein mit der Zeit vergeht, 
überstrichen ist. Und wie der Weise im bispel die wertvolle von der billigen Ware, das Gold vom Kupfer, unterscheiden kann, weiß die weise Frau, daß des staten Mannes triuwe ,ze allen citen niwe" (II 8 ) ist, während der unstate nur die Frauen betrügen will (126).

Teil A des bîspels vom „wilden Roß” (Ed. Nr. VII) zeigt, daß es unklug ist, sich auf einem unbändigen Roß festzubinden, um es zu zähmen, vor allem dann, wenn andere dies bereits vergebens versucht haben. Wenn das Roß stürzt, läuft der Reiter Gefahr, unter ihm begraben zu werden. Solch ein Pferd, deutet uns Teil $\mathrm{B}$, ist wie eine unstate Frau, die keinem Ritter die triwwe bewahren will und schließlich den allzu Eifrigen, der sie an sich binden will, ins Verderben stürzt, so daß am Ende ,ir beider ere tot” (I27) ist.

Auch Editionsnummer IX, „der Gärtner," offenbart die Vorliebe des Strickers für das Thema state. Hier wird der Gärtner, der zwei Gärten gleichzeitig besorgen will und dabei beide vertrocknen läßt, weil er der Aufgabe nicht gewachsen ist, mit einer Frau verglichen, die zwei Männern zu Willen ist und dabei beide verliert, weil ihre geteilte Aufmerksamkeit den Männern nicht genügt. Neben dem Verlust der Männer muß sie auch noch den ihrer êre beklagen, denn ihre anrüchige Tätigkeit läßt sich nicht verheimlichen. Am Ende wird sie dastehen wie eine schöne Blume „uf einer grozen chroten.” ( 156 )

In Editionsnummer X, „Frauenleben und Pfaffenleben,” wird von der Frau gefordert, daß sie scham (47), güete und tugent (50) habe und die Kraft besitze, denen zu widerstehen, die ihrer schône (35), ihres guotes (35) oder ihren hôhen muotes (36) wegen um ihre Minne werben. Sie ist der Gefahr der Versuchung mehr ausgesetzt, als die arme, häßliche oder tugendlose Frau, die weniger begehrt ist, wie auch der wort- und schrifterfahrene Pfaffe dank seiner Fähigkeiten größeren Versuchungen ausgesetzt ist als der ungelehrte, dem sich weniger Möglichkeiten der Schriftauslegung auftun.

Im „einfältigen Ritter” (Ed. Nr. XIII) mahnt der Dichter die Frau, tugentsam zu sein, denn der Ritter, der die tugent an einer Frau vermißt, kann diese nicht lieben, selbst wenn sie sonst sehr begehrenswert ist, weil sie Schönheit und Jugend besitzt.

Neben Begriffen, die auch in der höfischen Periode gängig waren, beschäftigt der Stricker sich auch mit solchen, die nicht mit der Gedankenwelt der klassischen Minnesänger zu vereinbaren 
sind. In Ed. Nr. V, „Kirchtag,” wird der Mann töricht geheißen, der sich „mit hercen und mit sinnen” (47) an eine Frau klammert, deren Gegenliebe er nicht erwarten kann. Indem er alle seine Kräfte daran setzt, sie zu gewinnen, verpaßt er durch sie manche andere Gelegenheit, wo ihm gebührender Dank sicherer gewesen wäre:

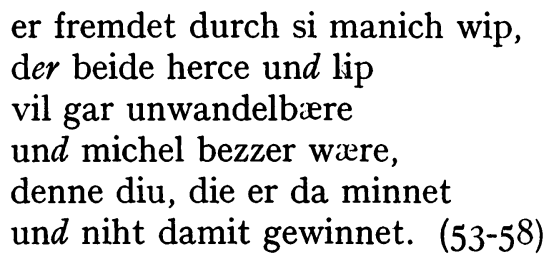

Solch eine Meinung wäre in der höfischen Periode als unhöfisch gebrandmarkt worden, denn gerade der vergebliche Minnedienst ist wesentlicher Bestandteil des hochhöfischen Minnedienstes. „Aber eben darin, daß der Lohn versagt wird, die Liebe wân bleibt, liegt das Wesen des hohen Minnedienstes."1

In Editionsnummer VIII, dem „Hort,” begegnen wir ähnlichen Gedanken wie in V. Auch hier wird der Mann aufgefordert, sich die Frau aus dem Sinn zu schlagen, die für ihn unerreichbar ist, sei sie auch noch so schön, ihr Gruß noch so hold und ihre körperlichen und charakterlichen Vorzüge noch so hervorstechend. Die Gefahr des Trennungsschmerzes sei zu imminent, um solch eine Minne zu rechtfertigen. Wiederum muß man feststellen, daß sich des Strickers Minnehaltung nicht mit der der höfischen Zeit in Einklang bringen läßt. Während dort der Trennungsschmerz, ja, die Möglichkeit einer Trennung, gerade das Element gewesen wäre, das den Dichter zum Minnesang angefeuert hätte, lehnt der Stricker solches als tump ab: „tumber man, daz lidest du!" (58)

Editionsnummern III und XI enthalten Themen, die sich abseits der Problemstellung des hochhöfischen Minnesangs befinden. Im bîspel von den "geliehenen Kleidern" (Ed. Nr. III) ermahnt der Dichter die Frauen, ihrer natürlichen Eingebung $\mathrm{zu}$ folgen und nur den tugentsamen Ritter zu lieben, statt nach dem Beispiel böser Frauen den Lockungen der niederen Minne zu erliegen. Verlust der êre und damit Unfähigkeit zur wahren

1 Helmut de Boor, Die höfische Literatur. Vorbereitung, Blüte, Ausklang. II70-I 250, München, ${ }^{4}$ I960, S. 255. 
Liebe wären gewisse Folgen eines solchen Lebenswandels. „Ehemanns Rat” (Ed. Nr. XI) besagt im wesentlichen, daß eine zu große Selbständigkeit der Ehefrau den Ehrverlust beider Gatten zum Ergebnis haben würde:

$$
\begin{aligned}
& \text { swa daz wip ze meister wirt erchorn, } \\
& \text { da hant si ir ere verlorn } \\
& \text { beide daz wip und der man. (203-205) }
\end{aligned}
$$

Obwohl im hohen Minnesang von der angebeteten Frau tugent, zuht, scham, und kiusche gefordert wird, richtet sich diese Forderung an eine verheiratete Frau (Hugo Kuhn spricht von der „Paradoxie solcher Ehebruchspoesie”). ${ }^{1}$ Der Stricker lehnt außereheliche Liebesbezeugungen mit der Begründung, daß es sich dabei um Ehebruch handle, kategorisch $a b$, indem er spöttisch bemerkt, daß man so etwas einst hôchgemuotiu minne geheißen habe:

Hie vor do man die huote schalt und des sumlich wirt sere engalt, daz er lie sin husfrowen die geste gerne schowen, do si ir triwe ubersach und ir reht und ir $e$ zebrach, daz hiez hohgemutiu minne. (XII, I-7)

Die „hohe tougen minne” (63), wie der Minnesänger in Ed. Nr. XII seine ehebrecherische Tätigkeit bezeichnet, wird vom Stricker aufs schärfste angegriffen, und die Minnesänger selbst geißelt er mit Ironie und Zynismus. Möge man dem Minnesänger, so fordert der Stricker, seine "edel bluomen, loup und gras" (235), „einen vogel, der wol sunge” (237) und „einen brunnen, der da sprunge" (238) ,under einer schonen linden" (239) zu Tische auftragen, dann würde er schon innewerden, was seine Kunst und sein Treiben wert sei! Einem Minnesänger gebühre es, „bi dem walde und bi der owen” (278) zu weilen, nicht aber in der Nähe des Stalles, denn ,ein sou und ein nahtegal / die singent ungelichen sanc" (282/83).

1 „Die Klassik des Rittertums in der Stauferzeit. I I 70-I 230,” in Geschichte der deutschen Literatur von den Anfängen bis zum Ende des Spätmittelalters (1490), Stuttgart, I962, S. I I 7 . 
Der Stricker verteidigt auch die von den Minnesängern verdammte huote und die unbeliebten merkare (siehe XII, I ff.), so wie er vor den sogenannten hofscharen boten (I75) warnt, die "dem tivel merent siniu chint" ( 176$)$.

Die Verteidigung der Ehe und die Ablehnung von außerehelichen Beziehungen ist zentrales Anliegen seiner Dichtung. Die Begriffe, die der Sphäre des hohen Minnesangs entnommen sind, müssen im Lichte dieser Erkenntnis gesehen werden. Die stcete, die er von den Menschen seiner Dichtung fordert, steht nie im Konflikt mit der stcete, minne oder liebe, die man der Ehefrau entgegenbringt. Seine Gedichte beschäftigen sich mit dem Verhalten von Ehepartnern oder Menschen vor der Ehe.

Die starren Formeln des höfischen Minnesangs werden beim Stricker aufgelöst und für das tägliche Leben neu gedeutet. Die Dichtung des Strickers richtet sich nicht nur an den Adel, sondern auch an die Bürger, des Strickers Standesgenossen. Seine bîspel sind öfters aus dem täglichen Leben genommen oder behandeln allgemeinmenschliche Probleme, mit denen sich der Einzelne leicht identifizieren kann. Vor allem aber ist es die verallgemeinernde Tendenz seines bîspels, die alle Standesschranken sprengt. Diese Verallgemeinerung trifft er gewöhnlich in der moralisatio, die dem Teil B seines bîspels folgt. Ein Beispiel möge genügen, diese Technik zu beleuchten. Obwohl die Charaktere im Teil A der „Königin vom Mohrenland” der Adelsklasse angehören, wird doch jeder Einzelne im Teil B angesprochen, denn hier verallgemeinert er in breiten $Z$ ügen, indem er eine ganze Reihe von allgemeingültigen, sentenzartigen Feststellungen gebraucht:

„swer noch hat zuht und scham [...]" (I06-II8).

„Swa vier werlichen stent [...]” (II9-I28).

"ez enwart nie berch so herte, [...]" (I29-I38).

„Swer lange dienet ane danch, [...]" (I39-I44). 


\section{II. Übersicht der Handschriften und Drucke}

Parallelhandschriften

$A 39$ (28rb-29ra) $H$ I43 $K$ I34*

$A 40(29 r a-29 v b) H$ I44 $K$ I35

$A 56$ (40va-4I $b$ b) $H$ I63 $K$ I54

$A 57$ (4Irb-4Ivb) $H$ I64 $K$ I55

$A 5^{8}(4 \mathrm{I} v b-42 r b) H$ I66 $K$ I57

$A 59(42 r b-43 r b) H$ I67 $K$ I5 8

$A$ 6I $\left(45^{r a-45 v b) ~} H\right.$ I74 $K$ I65

$A$ 7I (53va-54ra) $H$ I65 $K$ I56

$A 72(54 r a-54 v b) H$ I42 $K$ I33

$A 74\left(55^{r b-55 v b)} H \mathrm{I} 62 a K \mathrm{I} 53 c\right.$

$A 95$ (67ra-68ra) $H$ II7 $K$ I05

$A$ I55 $a$ (I2Ira-I22rb) $B 4_{2} E 56 I 39$

$A I 55 b$ (I22rb-I.22vb) $B$ 6IE $57 I 56$

A $204\left(I_{52 r a-152 r b) ~} B 50 E 29 F 2\right.$
Drucke

$H, \mathrm{II}-\mathrm{II} 4^{* *}$

$H$, II4-I 6

$H, \mathrm{I} 36-\mathrm{I} 38$

$H, \mathrm{I} 39-\mathrm{I} 40$

$H, \mathrm{I} 42-\mathrm{I} 43$

$H$, I43-I 46

$H$, I52-I 54

$H$, I4I-I 42

$H$, I09-III

$H$, I35-I36

$H$, I00-I03

$F$. von der Hagen

(Bib. A, 27), 295-299, nach $A$

F. von der Hagen

(Bib. A, 27), 299-301, nach $A$

F. Pfeiffer (Bib. A, 20), 339-34I, nach

$$
H \text { I40 } I 46 K \text { I3I } b
$$

$A, E, H$.

H. Mettke (Bib. A, 8), I45-I46, nach $A, E, H$.

* Numerierung von $K$ erfolgt nach Konrad Zwierzinas Zählung (Mikrofilm, Universität Graz).

** Die folgenden in $H$ enthaltenen Strickergedichte wurden von Gustav Rosenhagen herausgegeben (Bib. A, I3). 


\section{Literaturverzeichnis}

A. SPRACHE, ÜBERLIEFERUNG, METHODIK

I. Karl Bartsch, Hsg. Karl der Große von dem Stricker, Leipzig, I857. Neudruck mit Nachwort hsg. von Dieter Kartschoke, Berlin, I 965.

2. Franz Brietzmann, Die böse Frau in der deutschen Literatur des Mittelalters, Berlin, I9I2.

3a. Der Stricker. Füntzehn kleine Verserzählungen mit einem Anhang: Der Weinschwelg, hsg. von Hanns Fischer, ATB LIII, Tübingen, I96o.

3b. Der Stricker. Verserzählungen. I, 2., neubearb. Aufl. II, Mit einem Anhang: Der Weinschwelg, hsg. von Hanns Fischer, ATB LIII, LXVIII, Tübingen, 1967 (enthält zwei in za nicht enthaltene Texte).

4. Der Stricker. Tierbispel, hsg. von Ute Schwab, ATB LIV, Tübingen, 1960. 2., erg. Aufl. I968.

5. Wolfgang Dittmann, Rez. von Hanns Fischer: Der Stricker, ATB LIII, in Wirkendes Wort XII (1962), I84-I87.

6. Bern. Jos. Docen, in Miscellaneen zur Geschichte der teutschen Literatur I (I807), 5I-56; II (I807), 2 I I-227.

7. Gertraud Eder, Die Reimverhältnisse im Karlsepos von dem Stricker, Diss. Wien, I952.

8. Fabeln und Mären von dem Stricker, hsg. von Heinz Mettke, ATB (Halle) XXXV, Halle, 1959.

9. Hans Fischer, Rez. von Ute Schwab: Die bisher unveröffentlichten geistlichen Bispelreden des Strickers, in Anzeiger für deutsches Altertum und Literatur LXXII (1960), 76-82.

Io. Hans Joachim Gernentz, Rez. von Heinz Mettke: Fabeln und Mären von dem Stricker, ATB XXXV (Halle), in Deutsche Literaturzeitung fïr Kritik der internationalen Wissenschaft LXXXII (196I), 438-440.

I I. Karl August Hahn, Kleinere Gedichte von dem Stricker, Quedlinburg und Leipzig, I839.

I2. Arthur Hübner, „Grundsätze für die Herausgabe und Anweisungen zur Druckeinrichtung der Deutschen Texte des Mittelalters. Neue Folge," DTM XXXVIII (1934), V-IX.

13. Kleinere mittelhochdeutsche Evzählungen, Fabeln und Lehrgedichte. Die Heidelberger Handschrift cod. Pal. germ. 34I, hsg. von Gustav Rosenhagen, DTM XVII, Berlin, I909. 
14. Hans Lambel, Evzählungen und Schwänke, Leipzig, ${ }^{2}$ I 883 (I. Auflage I872).

15. Mären von dem Stricker, hsg. von Gustav Rosenhagen, ATB XXXV, Halle, 1934.

16. Maria Maurer, „Die Frauenehre” von dem Stricker, Diss. Karlsruhe, 1927 .

I7. Hermann Menhardt, Verzeichnis der altdeutschen literarischen Handschriften der Österreichischen Nationalbibliothek I, Berlin, I96o.

I8. - , „Zu Strickers kleinen Gedichten," in PBB (Tübingen) LXXXII (1960), 321-345.

19. Heinrich Niewöhner, "Strickerhandschriften," in $P B B$ (Halle) LXXVII (1955), 495f.

20. Franz Pfeiffer, „Der einfältige Ritter,” in „Altdeutsche Beispiele,” in Zeitschrift für deutsches Altertum VII (1849), 339-34I.

21. Gustav Rosenhagen, Untersuchungen über „Daniel vom Blühendtn Tal" vom Stricker, Diss. Kiel, 1890.

22. Arno Schirokauer, ,Studien zur mittelhochdeutschen Reimgrammatik," in $P B B$ XLVII (I923), I-I26.

23. Gabriele Schieb, „Editionsprobleme altdeutscher Texte," in Wissenschaftliche Zeitschrift der Ernst-Moritz-Arndt-Universität Greifswald XV (1966), 523-533.

24. Ute Schwab, Die bisher unveröffentlichten geistlichen Bispelveden des Strickers, Göttingen, 1959.

25. -, Rez. von Hanns Fischer: Der Stricker, ATB LIII, in PBB (Tübingen) LXXXIII (I96I), 373-382.

26. Karl Stackmann, „Mittelalterliche Texte als Aufgabe," in Festschrift für Jost Trier zum 70. Geburtstag, 1964, 240-267.

27. Friedrich von der Hagen, „Die Minnesinger," in "Aus dem Weltund Sittenspiegel vermutlich vom Stricker," in Germania VIII (I 848), 295-299.

28. Karl Waelzel, Reimwörterbuch und Verzeichnis der Reimwörter aus „Daniel von dem Blïhenden Tal" und dem „Pfaffen Amis," München, 1926.

29. Konrad Zwierzina, „Mittelhochdeutsche Studien," in Zeitschrift für deutsches Altertum XIIIV (1900), I-II6; 249-3I6; 345-406; XLV (I90I), I9-IOO; 253-4I9.

30. -, "Beispieireden und Spruchgedichte des Strickers," in Mittelhochdeutsches Ubungsbuch, hsg. von Carl von Kraus, Heidelberg, ${ }^{2}$ I926, 83-108; 279-287.

\section{B. LITERARISCHE DEUTUNG}

I. Erhard Agricola, Die Komik dev Strickerschen Schwänke, Diss. Leipzig, 1954 .

2. -, „Die Prudentia als Anliegen der Strickerschen Schwänke. Eine Untersuchung im Bedeutungsfeld des Verstandes," in PBB (Halle) LXXVII (1955), I97-220.

3. Anton Avanzin, ,Anmerkungen zu den Strickerischen bîspels der Melker Handschrift," in Germanistische Abhandlungen (Innsbrucker 
Beiträge zur Kulturwissenschaft VI), hsg. von Karl August Klein und Eugen Thurnher, Innsbruck, I959, I I I-I 27.

4. Clair Baier, Der Bauer in den Dichtungen des Strickers, Diss. Tübingen, 1938.

5. Albert Blumenfeldt, Die echten Tier-und Pflanzenfabeln des Strickers. Teil I, Diss. Berlin, I9I6 (ein weiterer, ungedruckter Teil behandelt: „Die Ethik der Fabelgruppe”).

6. Hanns Fischer, Strickerstudien. Ein Beitrag zur Literaturgeschichte des 13. Jahrhunderts, Diss. München, I953.

7. -, „Zur Gattungsfrage des ,Pfaffen Amis'," in Zeitschrift für deutsches Altertum LXXXVIII (I957/58), 29I-299.

8. - ,Neue Forschungen zur deutschen Dichtung des Spätmittelalters," in Deutsche Vievteljahrsschrift XXXI (1957), 303-345.

9. Ludwig Jensen, Über den Stricker als Bispel-Dichter, Diss. Marburg, I885.

Io. Hans Mast, Stilistische Untersuchungen an den kleinen Gedichten des Strickers mit besonderer Berücksichtigung des volkstümlichen und des formelhaften Elementes, Diss. Basel, I929.

II. Gustav Rosenhagen, Verfasser-Lexikon IV, Sp. 292-299.

12. Gabriele Schieb, „Das 'Bloch',” in PBB LXXIII (I95I), 422-429.

13. Ute Schwab, „Zur Interpretation der geistlichen Bispelrede,” in Istituto Orientale di Napoli. Annali Sezioni Germanica I (1958), I 53-I 8 I.

I4. -, „Beobachtungen bei der Ausgabe der bisher unveröffentlichten Gedichte des Strickers," in PBB (Tübingen) LXXXI (I959), 6I-98.

I 5. -, „Zum Thema des Jüngsten Gerichtes in der mhd. Literatur II," in Istituto Orientale di Napoli. Annali Sezioni Germanica IV (196I), I I-73.

I6. -, Die Barlaamparabeln im Cod. Vindob. 2705. Studien zur Verfasserschaft kleinever mhd. Gedichte, Napoli, I966.

I7. Wolfgang Spiewok, „1)er Stricker und die Prudentia," in Wissenschaftliche Zeitschrift der Ernst-Moritz-Arndt-Universitüt Greifswald. XIII (1964), II9-I 26.

I8. Siegfried Sudhof, Verfasser-Lexikon V, Sp. Io69-Io72. 
Modifizierter diplomatischer Text mit Varianten und

Wort- und Sacherklärungen 



\section{Die Königin vom Mohrenland}

\begin{tabular}{cl}
$28 r b \quad$ & \multicolumn{1}{c}{ Ez was hievor ein chunigin, } \\
diu moht wol ein vrowe sin: & si het geburt und gwalt, \\
& ir richeit was manichvalt. \\
5 & si het vrowen tugende gar, \\
& rosenvar und lilgenvar \\
& was ir vil minnechlicher lip: \\
& si was ein wol gemachet wip, \\
& ir lop erschal in elliu lant. \\
Io & die besten riter, die man vant \\
& uber allez ertriche, \\
& die vant man stætichliche \\
& in ir hove und in ir lande. \\
& ir hove stunt ane schande, \\
I5 & unz des tivels boten quamen \\
& und ir gar benamen \\
& beide ir freude und ir sin. \\
& ez het ein heidenin \\
& bi der vrowen lange ein lant; \\
$28 v a$ & swaz man liute da inne vant, \\
& ez wær man ode wip, \\
& die heten alle swarzen lip. \\
da sante diu heideninne dar & vil wibe, die warn morvar,
\end{tabular}

A 39. $\quad H 143$

Uberschrift in $H$ :

Ditz mere von einer kvnigín if $t$

Vñ võ eíner kvnigĩ vz mozen lant

3 Si het geburt - „Sie war aus vornehmem Geschlecht"

6 ligen $A$; lylien $H$

I3 $\mathrm{v}$ in hove Ansatz zum $\mathrm{b} A$

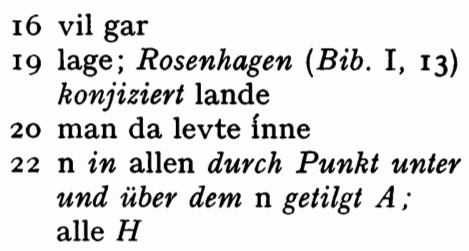

I6 vil gar

19 lage; Rosenhagen (Bib. I, I3) konjiziert lande 20 man da levte ínne

$22 \mathrm{n}$ in allen durch Punkt unter und über dem $\mathrm{n}$ getilgt $A$; alle $H$ 
25 in der vrowen chunichrich, daz si da tougenlich den ungelouben lerten und die riter da vercherten. daz geschach in churcen stunden.

30 swen si uberwunden, daz er ir leben anegie, der wart swarz als sie und wart in gar gehorsam. do man ze hove daz vernam,

35 do zurnt diu chuniginne so sere, daz si ir sinne von dem zorne verlos und alle ir wisheit verchos. si sprach: „nu wizzet alle daz:

40 ichn habe iuch nimmer deste baz, daz ir belibet unvercheret. swer got damit niht eneret, der tu swaz im gevalle!" do sprachen die riter alle:

45 ,ist daz wir got und iu gestan, des sult ir uns geniezzen lan. welt ir uns des niht danch sagen, damit meget ir uns verjagen und mugt uns gar verliesen."

50 "die got wellent verchiesen, die wil ich," sprach si, "han verlorn." durch den vil ungefugen zorn wurden da gnuge heiden und begunden sich scheiden

55 mit ir glouben von gote und von der kuniginne gebote.

28 vercherten - ,vom rechten Wege abbrachten"

30 [ie des vber

38 verchos - „aufgab"

39 das erste $\mathrm{z}$ in wizzet ist undeutlich $A$

40 Ich en gehabe. baz haben „besser behandeln"
4 I belibe $A$; belibet $H$

45 gestan + Dativ - „stehen zu jmd."

48 das erste e in meget alemannisch-bairische Nebenform zu dem häufigeven $\mathrm{u} A$

$54 \mathrm{~g}$ in begunden Ansatz zum $\mathrm{b} A$ 


\begin{tabular}{|c|c|c|}
\hline & 57 & daz hete maniger verlan, \\
\hline & & $\begin{array}{l}\text { wolt sis im gedanchet han. } \\
\text { don wolt sis in niht danchen. }\end{array}$ \\
\hline & 60 & des begundens alle wanchen. \\
\hline $28 v b$ & & sus wart der kuniginne chraft \\
\hline & & vercheret mit der heidenschaft. \\
\hline & & $\begin{array}{l}\text { Nu horet, waz ir geliche, } \\
\text { der kuniginne riche, }\end{array}$ \\
\hline & 65 & diu mit den ern genas \\
\hline & & $\begin{array}{l}\text { und so gar volchomen was: } \\
\mathrm{d} a z \text { was diu werlt in der zit, }\end{array}$ \\
\hline & & $\begin{array}{l}\text { do sich vroude und ere enwiderstrit } \\
\text { liezen horn und schowen }\end{array}$ \\
\hline & 70 & $\begin{array}{l}\text { beidiu an rittern und an vrowen. } \\
\text { do si an einander dinest barn }\end{array}$ \\
\hline & & $\begin{array}{l}\text { und beide einander warn } \\
\text { mit hercenlichen triwen holt }\end{array}$ \\
\hline & & und michel lieber danne golt, \\
\hline & 75 & do sach man durch werden lip \\
\hline & & $\begin{array}{l}\text { die werden riter hohe varn, } \\
\text { weder lip noch gut sparn. }\end{array}$ \\
\hline & 80 & $\begin{array}{l}\text { ir tage, ir lip und ir gwin } \\
\text { gie durch die vrowen ere hin. }\end{array}$ \\
\hline & & $\begin{array}{l}\text { do was diu werlt gechronet, } \\
\text { mit freuden gar geschonet }\end{array}$ \\
\hline
\end{tabular}

57 hite $A$; Daz het $H$. Uber den Gebrauch des Präteritums von hân beim Stricker siehe Bib. I, 29, 44, IOI-I 16 und 294. 58 ín verlan - „unterlassen"

65 mit den ern - „mit Ruhm”. genas - ,am Leben blieb, lebte"

66 Vñ gar fo

67 Do $A$; Daz was $H$

68 Do si $A$; Doch [i vrevde $H$; Rosenhagen konjiziert do sich.

enwiderstrit — ,um die Wette"

69 horn - „hören"

$7 \mathrm{I}$ ein vor an fehlt. dinest barn - „Verehrung entgegenbrachten"

76 ir werdẽ

77 hohe - „stolz"

79 gwin - „Erwerb"

80 der vrowen. ere steht am Ende der Zeile mit Verweisungszeichen hinter vrowen $A$ 
83 und saz uf dem geluckes rade.

Do geschach der werlt ein solhe schade

85 als der kuniginne geschach, diu ir riter sich vercheren sach. also chom ein tugentloser sit, da wart diu werlt vercheret mit, daz man verschamter wibe phlach.

90 swelhe riter bi den gern lach, der wart ze hoher minne enwiht und enahte uf die vrowen niht. daz swartze heidenische leben hat sich manige $m$ riter geben,

95 der hohe minne hat verchorn. der habent die vrowen vil verlorn. dawider lazent die vrowen der kuniginne willen schowen, diu beide ir riter verlos

Ioo und ouch ir weisheit so verchos, daz si den niht danchen wolde, alsi von rehte solde, die sich niht wolden chern von ir triwen noch von ir ern. swer noch hat zuht und scham und vrowen minnet ane haz, den habent si ninder dester baz. damit laident si ir lip

IIo und liebent diu unstæd $i$ u wip

83 swaz $A ; \mathrm{V} \tilde{n}$ [az $H$. d $i n$ rade Ansatz zum $\mathrm{t} A$. geluckes rade - „Glücksrad (das sich wälzende Rad des Glückes)"

87 chom — „nahm überhand”. sit(e) - „mask.!"

89 verschamt - „schamlos"

Nach 90 zwei Mehrverse:

$90 a$ Vñ pflage der mínne

$b$ Daz er verlos die fínne

9I enwiht - „wertlos"

92 en achtet. die fehlt
93 heideniche $A$; heidenífches $H$

94 gegebẽ

95 Die hohe mínne hant $\mathrm{v}^{\mathrm{s}}$ lozn; Rosenhagen konjiziert verkorn

97 lazænt $A$. dawider — ,im Vergleich dazu". lazent schowen - „lassen sich aufzeigen"

I04 c in noch über dem o $A$

I08 ninder - „nirgendwo, keineswegs"

I Io c über dem i in unstædun $A$ 
III und machent den unstæte, der nimmer missetæte, $\mathrm{ob}$ in die vrowen liezzen siner tugende so vil geniezzen,

II5 daz si im danch ruhten sagen. sol er si in dem hercen tragen un $d$ si in bi der cehen niht, daz wirt ze jungist gar enwiht. swa vier werlichen stent

I20 und in wol zweinzech abegent, swer si des niht geniezzen lat, daz dunchet mich ein missetat. sit vrowen maniger abeget, swer noch in ir gebot stet,

125 der solde in vor in allen sein. ist des niht, so tuont si schein, daz si der riter niht engernt und gerne ir dienstest enbernt. ez enwart nie berch so herte,

I30 der in mit brechen zerte und daz die lenge tæte, ern zefurhte sine stæte, daz er davon muse zergen. wie solt ein riter denne gesten,

I35 den man mit ungenaden zert und im sin hohgemute wert? fur vreude ist niht so gut,

II3 ob - ,wenn"

I 44 siner ... geniezzen - ,seine guten Eigenschaften (z. B. zuht und scham) soweit anerkennen würden." tugende - "Gen. sg."

I 5 fi ír ím danck gervchen. ruhten - "geruhten"

I 7 beder $A$; ín der zehen $H$

I I9 werlichen stent - ,standhaft bleiben"

I 20 Swa ín wol zweínzick; Rosenhagen konjiziert: und in. zweinch $A$. abegent - ,abtrünnig werden"

I25 [ol voz ín; Rosenhagen: sol in vor. e in sein $\ddot{u b e r}$ dem i $A$

126 tvt; Rosenhagen: tunt. e in schein ïber dem i $A$. tuont si schein — „bekunden sie"

I 28 dienes

I 3 I die lenge - „lange genug"

I32 er zv fvrte. zefurhte ,zerriß durch Furchen”

I 33 da mvi te $z v$ gen

I34 [ol

I 37 niht - ,nichts" 
I38 so der dem manne iht liebes tut. swer lange dienet ane danch,

I40 tut der ze jungist einen wanch, daz ist an im gemachet.

damit ist der geswachet, der im da lonen solde und im niht lonen wolde.

$13^{8}$ niht $A$; iht $H$

140 er zv. ein weiteres c über c in wanch $A$
I4I gemachet - "passend"

142 er 


\section{Das Wildpret}

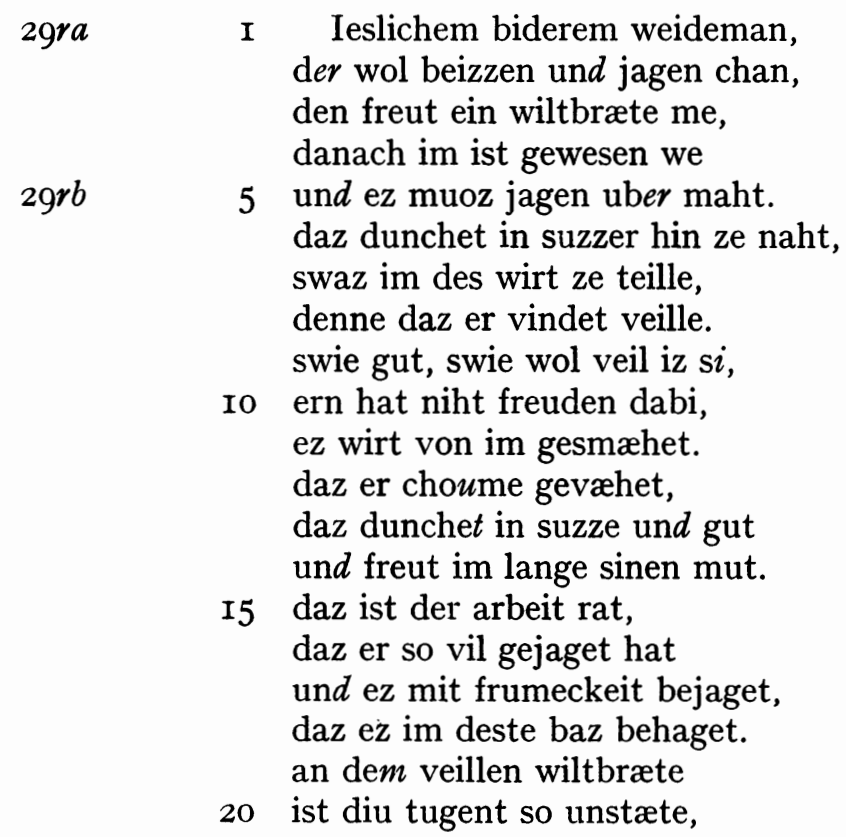
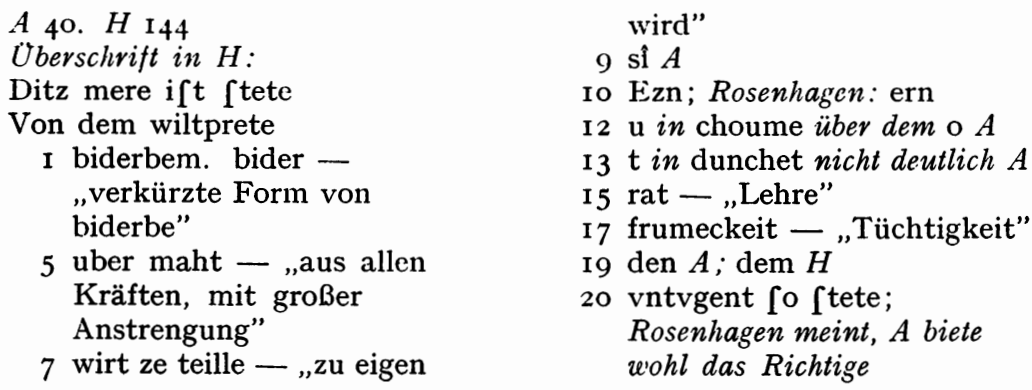
2I daz ez dem rehten weideman dehein freude gemachen chan. ez freut niht wan frazze: die ezzent ez ane mazze.

25 Des veilen wiltbrætes sit volget veilen wiben mit. swie schone ein veille wip si, ir minne ist niht freude bi. ezn wirt dehein veilliu brout

30 dem wisem manne nimmer trout, si chumt den toren ze mazze sam daz veil wiltbræt ze frazze. si ist niht freudebære dem hofschen minnære.

35 den freut michel baz ein wip, durch die er gut und lip arbeiten und wagen muz. so er ir hulde und $i$ r gruz ie chumberlicher bejaget,

40 so im ir lip ie baz behaget; so er tage und arbeit und sin chost an si geleit, so gelustet in des wibes. so er sele und libes

45 muz angest umbe ir minne han und hat die vorht und den wan, ob ers an ir schult verliese,

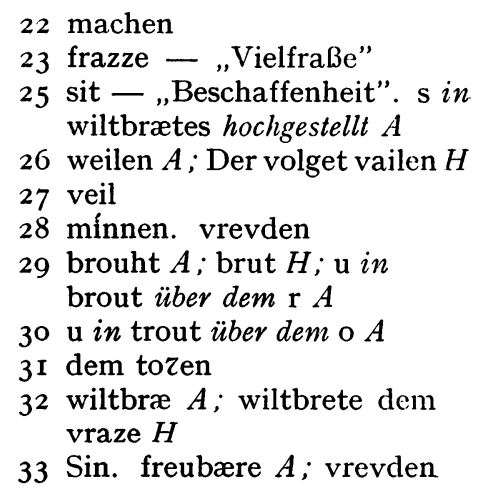

\section{bere $H$}

34 hvb [chen

38 er $A$; ir grvz $H$

39 chvmberlich; Rosenhagen folgt $A$

4I Swenne er

43 geluste $A$; gelv [tet ín des libes des wibes $H$; Rosenhagen streicht des libes

44 sele und libes — "mit Leib und Seele (Gen.)"

$46 \mathrm{~h}$ in vorht undeutlich $A$; vozcht $H$

$4^{8}$ vil gar 
48 daz si in gar verchiese, er muz gewarten ir gebotes

50 flizchlicher denne gotes, und muz tuon allez, daz si wil. diu minne ist sines hercen spil. er wirt ein vreudenricher man, daz er so wilde minnen chan

55 gwinnen und behalten, daz er ir chan gewalten. diu fuoge und diu bescheidenheit die machet, daz er der arbeit mit vreuden wirt ergetzet.

60 er slifet und wetzet sine manheit und sinen sin, swenne er gewinnet den gwin, der nimmer manne wirt bereit, er muoz zu der frumicheit

65 haben zuht, fuge und chunst. swelich ritter gutes wibes gunst mit sinen tugenden chan bejagen, der muz im selben wol behagen. sin leben ist wol freuden wert, 70 so im sin chunst eins wibes gwert, diu niht wan tugende minnet. swie choume er die gwinnet, mit swelhen noten ez erge, si birt im maniger freuden me

75 danne die er choufen solde. swie wert diu wesen wolde, si birt im niht so hohen mut, als diu verdiente tut;

49 wazten ir gebot

50 got. in $A$ wird e oder i der Endung ec/ic oft synkopiert: flizchlicher

54 mínne

57 Die gefvge

$5^{8}$ machen

64 er muoz - „es sei denn, daß er habe"
$65 \mathrm{Zvcht}$ | fvge | haben vñ

$68 \mathrm{im}$ - „Reflexivpronomen im Dativ"

70 Swen ín [ín chvn [t des. gwert - „einbringt"

73 ergê $A$

76 das zweite e in wesen unklar $A$; we [en wolde $H$. solde $A$

77 Sine ber 


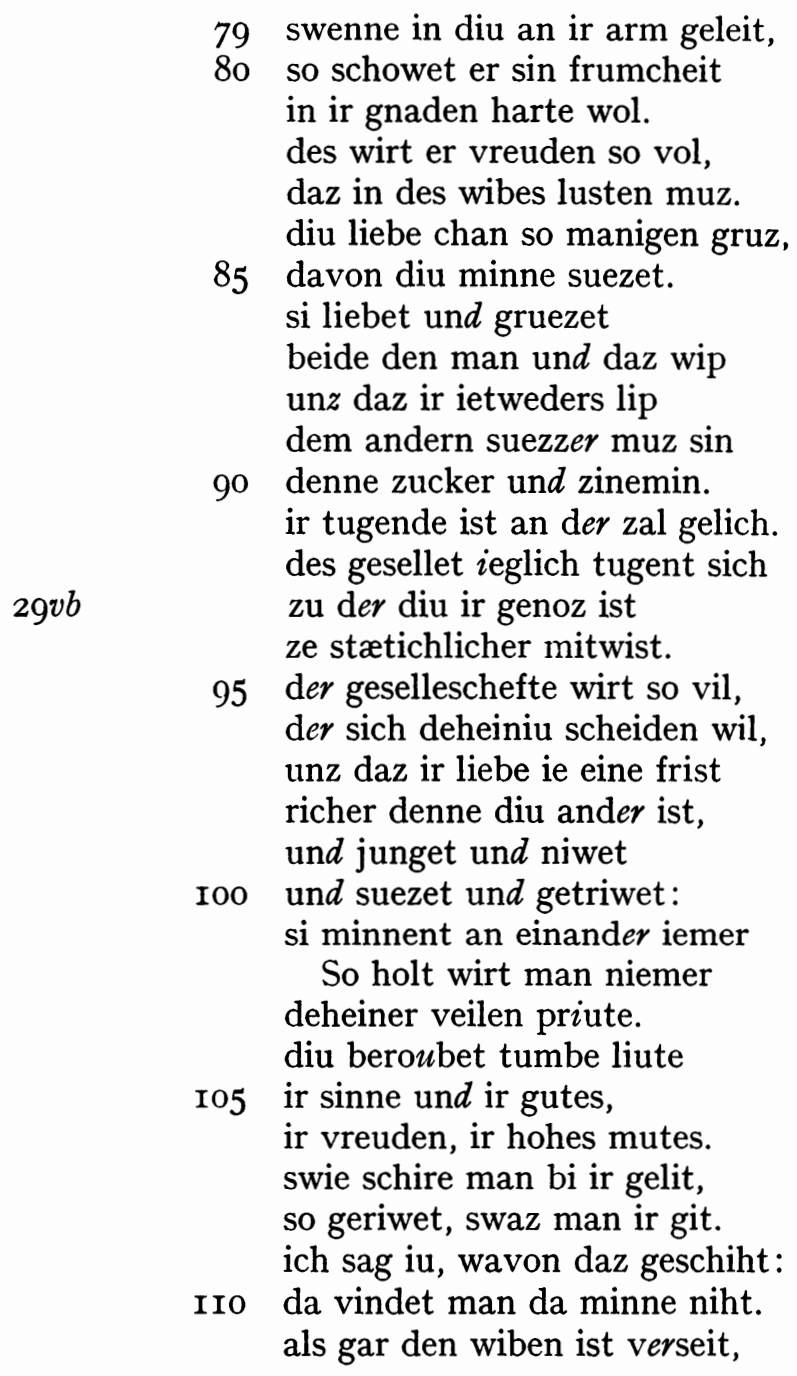

8I An ir

88 Und $A$; Vntz daz $H$

92 ie [lích $H$; îeglich $A$

94 mitwist - „Beisammensein”

99 jvnger vñ newer

Ioo $\int$ vzer vñ getrewer
I03 prute $A$; in $H$ ist der Reim brvte: levte

I04 $\mathrm{u}$ in beroubet ïber dem o $A$

I I I-I I 3 als gar ... als gar - ,wie es Tatsache ist, daß es den Frauen versagt ist, wieder 
II2 daz ir deheiniu werde meit, als gar verzert ein veile wip ane minne ir leben und ir lip.

II5 swaz dinges ich verchoufet han, des sol ich pillich ane gestan. swelich wip minne hine git, diune hat niht minne nach der zit. si hat nit und gitecheit,

I20 ir ist daz swære und leit, daz si dehein wip horet loben. ir herce muz vor leide toben, so man deheiner fur si gert. ir minne ist aller schanden wert.

I25 si hat des wucheræres mut. swer gar ir zweier willen tut, des sælde ist so verteilet, daz si nimmer wirt geheilet.

Jungfrauen $\mathrm{zu}$ werden, so steht es auch fest, da $\beta$ " II6 an [tan. pillich ane gestan - "rechtmäßig aufgeben” I 7 wip ír mínne
II 8 noch $A$; Die enhat niht mínne nach der $H$

I 22 herze mag voz

123 Daz man

I 27 ift gar verteilet 


\section{III}

\section{Die geliehenen Kleider}

I Ein riter der het michel gut und dabi so swachen mut, daz er entnomeniu chleider truch. und het doch selbe chleider gnuch,

5 diu wolde er an sich legen niht. do ergiench ein so getane geschiht, daz er den spot darumbe enphie, der im nach an sin herce gie. er leit an sich entnomen gwant

Io und reit da er manigen riter vant. die machten vreude und spil und guter churzwile vil, si warn hoflichen vro. ze jungist chom ez also,

I5 daz si zerren begunden, swaz si an einander funden. da was der riter allez mit und half in zerren nach ir sit, der ie gwant het entnomen.

$40 v b$

20 ez warn ouch dar mit im chomen, der gwant man ab in zarte.

die muete daz vil harte,

$A$ 56. $H$ I63

Uberschrift in $H$ :

Ditz ift ein fchöne mere genvck Wie eín Rítter entnom cleíder trvck

4 Er hete kleíder

5 Dinen wolt

$6 \mathrm{r}$ in ergiench hochgestellt zwischen e und $\mathrm{g} A$

8 ere

19 iê $A . \operatorname{der}$ - ,der riter (I 7), der"

20 Dar wazn. u in ouch über dem o $A$

2 I $\operatorname{im} A$; an $\operatorname{im} H$. ab in zarte — „Plusquamperfekt!” 
23 daz si ir chleider zerren sahen. do begunden si im zugahen.

25 ein riter zornchlich sprach: „sit ich iuch dunche so swach, daz ir mir lat zerren min gwant, deiswar, ir lazzet mirz zehant. ir habet wider mich getan.

30 swaz ich mere gwandes han, daz wil ich vor iu vrien.

lat die sukenien!" do er dem die sukenie lie, ein ander riter dar gie

35 und zoch im ouch den rok abe. er sprach: „swaz ich gwandes habe, des gebitet mich nimmer mere. mich muet daz harte sere, daz mir min rok gezerret ist.

40 iu sint nach dirre vrist miniu chleider iemer fremde. lat mir bruch und hemde." do sprach der riter: ,daz ist min. wie solde ich so nærrischer sin,

45 daz ich iu daz min liezze? swie harte iuch sin verdriezze, ir lat mir hemede und bruch!" ez wære hose oder schuch, si namenz allez wider.

50 si w $\imath$ rfen in dernider und machten in mitalle bloz.

24 begonde im. do ... zugahen - "da liefen sie auf ihn zu"

25 ṽ̃ $\int$ prach

28 Weizgot ír

30 ich her nach gewande[

32 mir die. sukenie „Kleidungsstïck (über dem Rock und unter dem Mantel getragen, zuweilen auch unmittelbar über dem Hemde)"

34 iê $A$
37 gebitte

38 mvte. c in mich über dem i $A$ 40 dirre [elben vrift

43 Sprach der dritte daz

44 Wes [olt ich nv fo nerrifch. nærrischer - „starke Flexion des Adjektivs"

46 hazte ez evh bedríeze

48 o in oder undeutlich $A$; oder $H$

5 I mitalle - ,gänzlich, ganz und gar" 
52 swie in des dienestes verdroz, er musez iedoch liden, sine wolden ez niht vermiden.

55 die riter liefen alle dar und namen siner noete war und fragten waz im wære. do sagt man in daz mære, daz er fromdiu chleider fuorte

60 und diu sinen ninder ruorte. des phlage er alle sine tage. „so lazze wir ez ane chlage," begundens allesamt jehen, „swaz im hie leides ist geschehen.”

65 sus wart er ze uneren und muse danne cheren unwerder denne er $e$ was. swi chome er vor der not genas, daz muse er lazzen ane zorn.

70 sus het er beidenthalp verlorn und was unwerder dann $\mathrm{e}$; man lech im ouch niht chleider me.

Dem riter tut geliche ein edele vrowe riche,

75 die got vor manigem wibe an sinnen und an libe mit tugenden hat gechroenet

\footnotetext{
52 bedroz. dienestes "Behandlung"

53 Er mv [ten iedoch

54 vermiden - „bleiben lassen, unterlassen"

$5^{8}$ [agte

59 fromd - „Nebenform zu fremd". Evgänzungsstrich zum $\mathrm{m}$ in fromdiu über der Zeile nachgetragen $A$; vremde $H$

6 rurte $A H$

6I phlege mit kleinem a über dem e $A$; wohl Korrektur des e; in der 1. und 3. Sg. Ind. Prät.
}

\author{
von starken Verben wird \\ zuweilen in Angleichung an \\ die schwachen Verben ein $\mathrm{e}$ \\ angehängt (siehe Hermann \\ Paul und Walther Mitzka, \\ Mittelhochdeutsche \\ Grammatik, Tübingen, 1960, \\ $\S$ I 55, Anm. 6) \\ 62 n (I. Pers. Plur.) kann \\ ausfallen vor wir. lazze -- \\ ",sein lassen" \\ 69 lazzen - „zulassen” \\ 73 Versalien in Dem
}

67 ê $A$

7 Er waz 
78 und in allen wis gescoenet, und ir git guter sinne vil,

80 der si doch niht geniezzen wil. als ir der besten einer gert, der wol ir minne wære wert so cheret siz ze ungewinne und læzzet alle ir sinne

85 und alle ir wisheit underwegen und wil et fremder sinne phlegen. si nimt niht in ir mut wan daz die andern dunchet gut, vor den si niht verheln wil.

90 ir si wenich oder vil, swaz die wellent, daz geschiht. diu minnet mit ir hercen niht; sie wil treuten und minnen mit anderre liute sinnen.

95 swer ir minne chan bejagen, der sol irs nimmer danch gesagen, sit siz an ir herce tut und an ir lip und an ir mut und volget fromder liebe mit.

Ioo diu hat des riters sit, der selbe chleider hete genuch und doch fromdiu chleider truch. als im ze jungist geschach, do man im diu chleider abebrach

I05 und er in schanden wart gesehen, reht alsam muoz ir geschehen, so si an ir selber sinne gestet und ir an den fromden misseget.

78 sc auf dem Rand mit Verweisungszeichen über durchgestrichenem $\mathrm{z}$ in gescoenet $A$

$84 / 85$ læzzet underwegen "mißachtet"

86 et - „nur, bloß (Variante von eht)"; ot $H$

87 in niht ín
88 Wan al die

89 [iz

96 Tols ír

98 liebe

IOI felbe fehlt

102 Vñ allez vremde

Io6 ovch ír

107 [tet 


$\begin{array}{ll}\text { Io9 } & \text { mit der ougen si gesach, } \\ \text { IIo } & \text { mit der munde si sprach, } \\ & \text { mit der orn si vernam, } \\ \text { der huete si ze huete nam, } & \text { der mute si da nachfuor, } \\ \text { der liebe ir liebe hulde swuor. } & \text { si entnam da willen und gunst, } \\ & \text { sam tet si wisheit und chunst. } \\ & \text { swenne ir daz allez abeget, } \\ & \text { wie eren bloz si danne stet, } \\ & \text { sam der riter von dem gwande! } \\ \text { I20 } & \text { noch grozzer wirt ir schande, } \\ & \text { swenne si ze mærn wirt } \\ & \text { und aller werdicheit enbirt. } \\ & \text { waz sol ein wip mere, } \\ & \text { swenne si wirt ane ere? } \\ \text { I25 so sol man sich ir getroesten } \\ \text { und gelichen zu den boesten. }\end{array}$

IO9-II4 der - „Genitiv des Demonstrativpronomens!"

I 3 Dem

I 5 entnam - „entlieh"

I 6 sam tet si - „wie auch"

I $2 \mathrm{I} \mathrm{zV}$ vneren. ze mærn wirt "ins Gerede kommt" I 22 ver írt
123 vrowe

I25 sich getroesten + Genitiv "verzichten auf"

I26 Sie i [t bo [er danne die boften. gelichen zu ,vergleichen mit, gleichstellen" 


\section{Die zwei Herren}

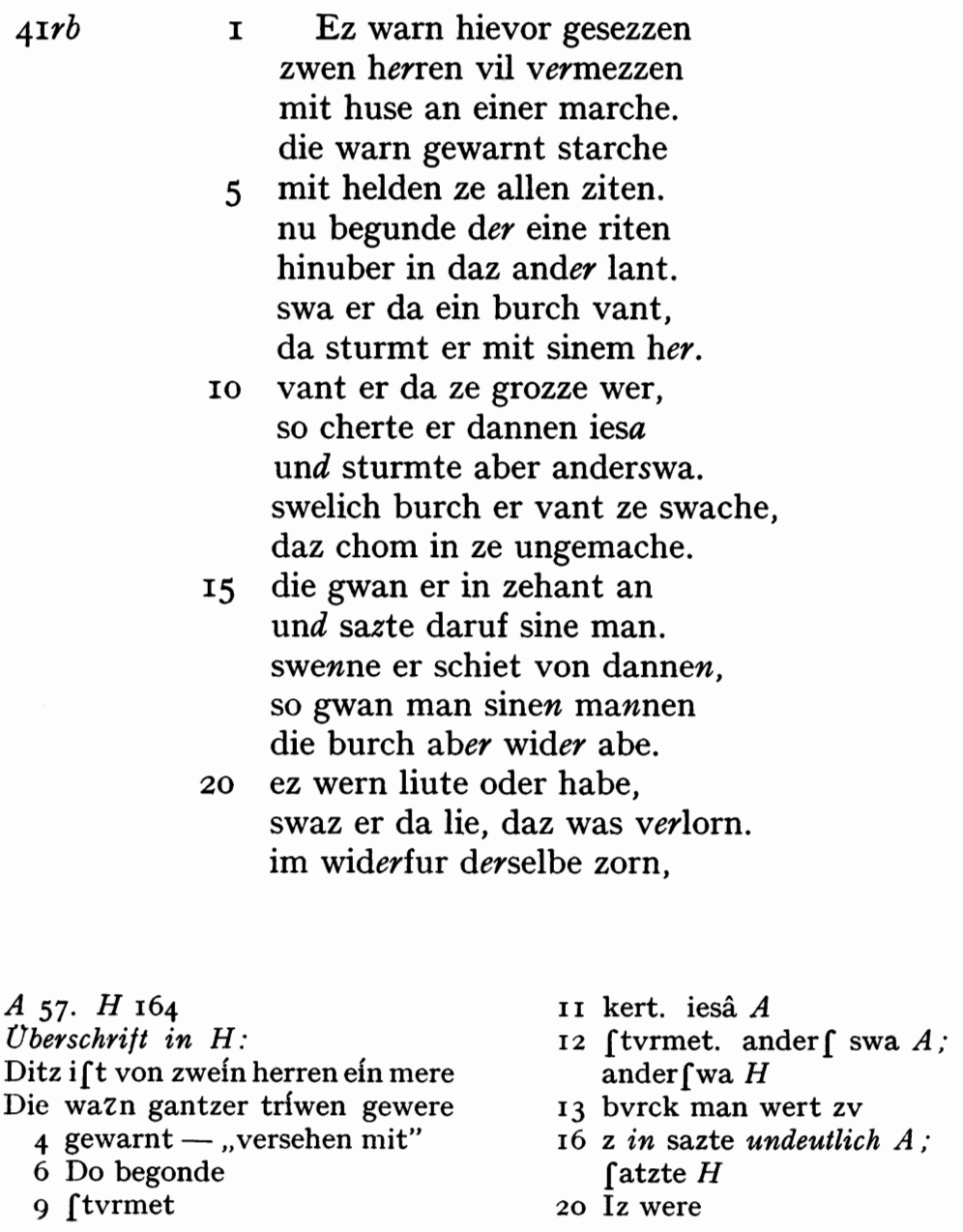


23 den er in $e$ het getan, die im die burch musen lan.

25 Der ander herre reit ouch dar. der nam der besten burge war, die er in dem lande $i$ ender vant; fur die saz er zehant. daz was der burchgraven spot.

30 die sprachen, ez entæte got, si gw $u$ nne in anders niemen an. er wære ein harte tumber man, daz er sich daz ane næme, des er nimmer ze ende quæme.

35 si wærn der burch an angist, die wile si ir aller langist zu einer burch wolden ruchen. ern dorfte ez nimmer versuchen, sin arbeit wurde gar enwiht.

40 daran chert er sich niht. er hiez rihten an den berch alle der hande antwerch, diu ze sturme frum warn und begunde der burch varn,

45 ob der erde und darunder, und begie so manich wunder, daz er in doch ze jungist an die burch mit sturme gewan. die boute er vroeliche

$5^{\circ}$ und wart daruffe riche; im muse dienen liute und lant. des arbeit was baz bewant,

23 e fehlt $H$; ê $A$

25 Versalien in Der

27 íme. lender $A$

29 das erste $\mathrm{r}$ in burchgraven über dem c $A$

3I Sine

33 Rosenhagen konjizieri des ane gegen $A H$

35 angst $A$; ange $[\mathrm{t} H$
37 ruchent $A$; rvchen $H$

38 ez níht. vs [vchent $A$; v' [vchen $H$

44 varn + Genitiv - "streben nach (Genitiv steht, wenn das Verbum eine Hinwendung auf ein Ziel bezeichnet)"

45 ob - „oberhalb"

5 I dienen daz lant 
53 denne des, der die boesen burge chos, die er schire gwan und verlos.

$55 \mathrm{Nu}$ wil ich iu bescheiden, waz de $n$ gelich tut beiden:

daz tun zwen minnære. den ainen dunchet swære, daz er minne ein stæte wip.

60 sin herce læzzet sinen lip niht muten solher eren. daz heizzet in zucheren, da im diu minne si bereit ane chost und an arbeit.

65 swelich minnære also minnet, swelich wip er also gwinnet, gwunne er der ein lant vol, die gwinnet ouch ein anderre wol. dem geschiht als dem man,

70 der die boesen burge gwan, die er schir gwan und schir verlos. der die besten burch erchos und die gwan mit grozzer not unde si unz an sinen tot

75 mit grozzen vrouden behielt und maniger eren daruf wielt:

Dem tut ein stæter man gelich, der an ein wip wendet sich, diu nach des wunsches lere

80 uf stæte und uf ere geedelet und getugent ist. der muz vil manigen guten list in ir dieneste versuchen. sol si sin dannoch ruchen,

53 des fehlt. bo[ern

54 [chír v'slos

55 Versalien in $\mathrm{Nv}$

56 gelichet beiden

6I muten + Genitiv "begehren"

62 heizzen $A$; heízet $H$. zuchern $A ;$ zv keren $H$
69 ienem man

72 die aller boe [ten bvrck chos; Rosenhagen konjiziert besten

76 wielt — „starkes Verbum!"

77 Versalien in Dem

78 gewendet 
85 da horet solhiu meisterschaft zuo, e si sines willen iht tuo, daz man nie burch so chume ervaht. er muz von stat und uber maht arbeiten gut und lip,

90 der ein gar volchomen wip mit dienest sol gewinnen. mit dem libe und mit den sinnen hat er ze tun ein michel teil. hat er ze jungist daz heil,

95 daz ir sin dienest angesiget, diu vroude, der er danne phliget, diu ist aller vrouden genoz. er weiz die stæete da so groz, daz er des gar an angest ist,

Ioo daz im deheines mannes list dehein schade an ir si. der sorgen ist er als fri sam iener uf der burge was, der vor den vienden wol genas.

I05 swer sich so wol versinnet, daz er den gwin gwinnet, den er niht mach verliesen, der chan vil rehte chiesen. swaz des gwinnet ein man, IIo des er behalten niht enchan, $\mathrm{der}$ gwin ist ungewære und ist niht vroudebære.

86 tu $A H$

$88 \mathrm{mvz}$ vber [tat

$92 \mathrm{~d}^{\mathrm{S}} \mathrm{e} A ; \operatorname{den} H$

95 ir ... angesiget — „daß er sie durch seinen Dienst erobert"

99 an fehlt $A$; gar an ange [t $H$
IoI ír minne $\mathbf{i}$

I03 $\mathrm{m}$ in sam undeutlich $A$; Sam $H$

I04 von den

Io9 Swaz er gewínnet der man

I I I ungewære - „unzuverlässig” 


\section{V}

\section{Der Kirchtag}

$4 \mathrm{I} v b$

$42 r a$

I Ez geschach von gwonheit, daz hievor ein riter reit uf einen chirchtach der was groz. da sahe er manigen sinen gnoz,

5 der er mit spise schone phlach, so si chomen uf sinen chirchtach. den ersten, den er da gesach, dem danchte er und sprach, do er in so wol enphie:

Io ,ich wil mit iu enbizzen hie." daz was dem andern riter leit, doch wart ez im niht verseit. er sprach: „daz dunchet mich reht.” do chom manich riter und chneht,

I5 die sich des alle flizzen, daz er wære mit in enbizzen. er sprach: „nu lat ez ane zorn, ir habt die bet gar verlorn. ich han hie einen guten wirt, 20 da mir vil wol noch hiute wirt." si liezzen beliben die bet. nu horet, wie sin wirt tet: er beite, daz er niht enaz

$A$ 58. $H$ I66

Uberschrift in $H$ :

Ditz mere if $t$ wie eín Ritter rait Vf einen kirchtack wol gemait

8 vor 7; Rosenhagen stellt nach A um

$8 \mathrm{c}$ in danchte $\ddot{u} b e r$ dem $\mathrm{n} A$
9 ín mít willekom enphíe

12 enwazt

I 4 chnet $A$; kneht $H$

I5 des flizzen - ,sich darum bemühten"

I 8 bet - „Abgabe"

$2 \mathrm{I}$ ir bet 
24 vil lange, niwan umbe daz,

$25 \mathrm{daz}$ der gast gienge anderswar. done wolde er ninder niwan dar.

des muse er ezzen lazzen

unz ander liute geazzen.

do des den gast betraget,

30 daz gesinde er do vraget, wa der wirt wære.

do sagten si im daz mære, ob er sin vastende bite, da soumet er sich selben mite;

$35 \mathrm{~d} e r$ wirt der wære daheime niht. sus was sin biten enwiht. do gie er $z u$ einem litgeben. swes er des tages solde leben, daz muse er allez gelten.

40 er begunde sich selben schelten, daz im so torlich geschach, daz er manigen guten wirt versprach und im einen wirt erchos, an dem er sin chiesen gar verlos.

45 Also geschiht noch einem man, der sich ein wip genimt an mit hercen und mit sinnen und wil die iemer minnen,

24 lange niht vmbe

26 wan dar

29 betraget - „verdroß"

30 $\mathrm{r}$ in vraget $\ddot{u} b e r$ dem $\mathrm{v} A$

3 I wirt [o lange were

32 sagt $A$. [agten [im $H$

33 ob er sin vastende bite ,wenn er hungernd auf ihn warte"

$34 \mathrm{u}$ in soumet über dem o $A$

35 der vor wære fehlt

36 biten - „Warten"

37 einer $A$; einem $H$. litgeben - „Schenkwirt”

38 Des er. leben + Genitiv "leben von". des tages - "während des Tages"

39 gelten - „bezahlen”

4 I tvmplích

42 versprach - ,Einladung abgelehnt hatte"

Nach 42 vier Mehrverse:

$42 a$ Vñ ím erkos einen wirt

$b$ Do er der [pi [e wazt ver írt. verirt - "beraubt"

c Al dem Ritter ge [chach. Versalien in $\mathrm{Al}[$

$d \mathrm{D}^{\mathrm{S}}$ mangen guten wirt $\mathrm{v}^{\mathrm{S}} \int \mathrm{p}^{\mathrm{s}} \mathrm{ch}$

43 chos. im - „reflexiv"

$44 \mathrm{Da}$ er [in chie[en verlos 
49 diu in niht wider minnen wil.

50 er gedenchet: „,mach ih ir vil gedienen mit rehten triwen, sine læt michz niht geriwen." er fremdet durch si manich wip, der beide herce und lip

55 vil gar unwandelbære und michel bezzer wære, denne diu, die er da minnet und niht damit gewinnet.

$42 r b$ so ist im gewesen al ze gach.

60 er volget siner stæte nach, unz si in ze jungist gar vergat und sich ouch dort versoumet hat, da man in gerne hete gesehen und im vil wære geschehen.

65 so hat ers bedenthalp verlorn, sam der dem wirt het erchorn, der im ze jungist entran. ez sol ein sinniger man vil wol erchennen den wirt,

70 durch den er guter wirte enbirt, und wol bechennen ein wip, durch die er tage, gut und lip beide swendet und cert und sich vil guter wibe wert.

75 ein jæger sol vil stritech wesen, ein wilt enmuge wol genesen, daz alle vart miden wil. mir ist ein dinch lieber vil, daz ich erwirbe in minen tagen,

80 denne daz ich chan nimmer bejagen.

5o $\mathrm{t}$ in gedenchet undeutlich $A$; gedenket mag $H$

59 so ... gach — ,so hat er sich zu sehr beeilt"

6 I vergat - „vermeidet”

65 er
66 der der den

69 bekennen

$7 \mathrm{I}$ bechennet

72 er gvt . tage . vñ

76 wilde mage

80 nímms kan 


\section{VI}

\section{Der Krämer}

$42 r b$

I Ein chramer fur durch gewin in eine stat. da braht er hin von golde solich chramgwant, daz man niht bezzers envant.

5 do er die kram ufgesluch, do wart des vil und genuch, des er darin leit und hiench. daz liut im vaste zugiench durch schowen und versuchen.

Io die da choufes wolden ruchen, den bot erz tiur, daz was reht. ,iwer werch ist darzu ze sleht, daz irz so tiur machet; ez wirt davon verswachet

I5 und wirt davon unmære." sus sprachen die burgære. er sprach: „swerz choufen sol, der muoz mirz gelten harte wol. ez ist wol hohes geldes wert.

20 swer ez erchennet und sin gert, der muz mir selbe des gestan, daz ich guten chouf gegeben han."

A 59. $H \quad H 67$

Uberschrift in $H$ :

Ditz if $t$ von eínem kramere

Eín vil [chones mere

5 den kram. kram „Krambude"

6 ez vil

9 vñ dvrch $v^{\mathrm{s}}$ [ vchen
Io $\mathrm{u}$ in choufes ïber dem o $A$

I 5 der von

I6 so

I 7 u in choufen über dem o $A$

I $8 \mathrm{mvz}$ iz

20 chennet vñ ez gert

$22 \mathrm{u}$ in chouf über dem o $A$ 
23 unz diu rede wart vernomen, do was ein anderre kramer chomen,

25 der sluoch ouch sine chrame dar. des chramgwant was goltvar und was von chopfer geworht. er was des gar unervorht, daz ie dehein man ersæhe

30 ein werch so rehte spæhe. swaz man da choufen wolde, daz bot er, als er solde, er bot ez umbe chleine gut. do wart der burgære mut

35 gefreut harte sere. si soumten sich niht mere. swaz ieslicher gevie, daz galt er froelich und gie hin wider heime mit schalle.

40 die burgære sprachen alle, si gesæhen nie so guten chouf. da wart ei $n$ michel zulouf. davon het er zehant verchoufet al sin kramgwant.

45 Ein wise man was in der stat, den vraget maniger und bat, daz er im rehte sagete, wie in der chof behagete. do sprach der witzege man:

50 ,ir gwinnet lutzel daran, swie wol iu der chouf gevalle." "habe wir denne verlorn alle," begunden die burgære jehen,

27 gewarht $A$; gewozht $H$

29 ge [ehe

30 rechte wehe

3I $\mathrm{u}$ in choufen $\ddot{u b e r} \operatorname{dem}$ o $A$

36 Sinen

39 mit schalle — ,übermütig laut"

4I Sinen. u in chouf $\ddot{u} b e r$ dem o A
42 eim $A$; eín $H$. u in zulouf ïber dem o $A$

$44 \mathrm{u}$ in verchoufet $\ddot{u} b e r$ dem o $A$

45 Versalien in Ein

46 Nach d Abbreviatur und hochgestelltes $\mathrm{n} A$; Den vraget H

48 ím

5I u in chouf über dem o $A$ 
54 "so ist uns harte wol geschehen,

55 daz wir so lutzel haben verlorn und den andern chouf han verborn, da michel mer verlorn wære. da ist ouch ein chramære, des chramgwant ist boeser vil.

60 swaz man des sinen choufen wil, daz biutet er so tiure, daz uns weder vert noch hiure nie chouf so hohe wart gelopt." ,ich wæne, daz er niht entopt,"

65 begunde der wise man jehen, „ir chramgwant wil ich sehen." si giengen mit im alle dar, die gerne wolden nemen war, ob er daz lobt eine,

70 daz si schulten alle gemeine. do er daz kramgwant gesach, bi sinen triwen er des jach, ezn solde niemen schelten, man solde ez hohe gelten.

75 er wolde sin choufen ein teil und wold ez haben fur ein heil, daz er dar chomen wære. do sprachen die burgære: „ez missevellet uns allen.”

80 „ez muoz mir wol gevallen," so sprach der witzige man. er truc vil froeliche dan, swaz er vergelten chunde.

56 u in chouf $\ddot{u} b e r$ dem o $A$. verborn - ,unberücksichtigt gelassen"

57 mære $A$; mer $H$

59 boeser - „schlechter"

60 [ines. u in choufen iiber dem o $A$

62 vert - ,im vergangenen Jahr"

63 u in chouf $\ddot{u} b e r$ dem o $A$
64 niht entopt - „vernünftig ist"

66 Des kramgewant. ge [ehen

69 lobte

70 schulten - „Präteritum von schelten"

7 I c in gesach über dem a $A$

75 woltes chovffen. $\mathbf{u}$ in choufen über dem o $A$ 
84 in einer vil churzer stunde

85 verdarp ir aller kramgwant, daz ubergulde daz verswant und wart als ein chopfer wirt, daz schonen schin von roste birt. daz was in allen harte leit.

90 des wisen mannes wisheit wart do gelobt deste me. swie im si niht volgeten $e$, si wurden im allesamt holt. si sahen wol, daz sin golt

95 ie schoner und schoner wart. "wir haben uns ubel bewart," begunden die burgære jehen, "uns ist vil rehte geschehen."

$\mathrm{Nu}$ wil ich iu bediuten,

Ioo waz dinges an den liuten der rede so nahen strichet, daz manz wol dar gelichet. swa des valschen mannes lip wirbet umbe ein rehtez wip,

I05 dem ist vil not und guot, daz er daz herze und den muot, diu chopher und untriwe sint und aller guter dinge blint, mit schonem golde schoene,

I Io untz er daz wip gehoene. spræche er nach sinem mute, daz choem im niht ze gute. davon muz siner gebærde schin und ouch rede so suezze sin,

87 Do wazt ez al

88 bó [en [chín

92 fim niht. ê $A$

95 Iê $A$

99 Versalien in $\mathrm{Nv}$

Ior der rede ... strichet - „der Erzählung so sehr ähnelt"

102 gelichet - ,vergleichen kann"

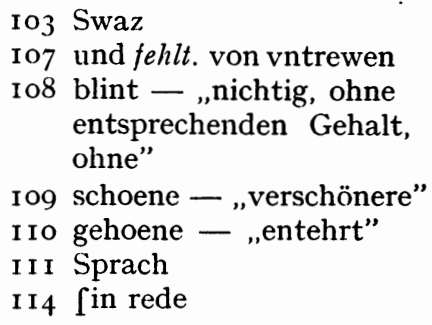


II5 daz nimmer ein getriwer man ein so gute rede erzewgen chan.

$43 r a$

Des rehten mannes triwe ist ze allen citen niwe, vil stæte und vil gewære:

I20 ern wirt niht lugenære. davon geheizzet er niht vil, durch daz erz allez leisten wil. so geheizzet der unstæte, ob erz vil gerne tæte,

I25 daz er doch muse liegen: der wil diu wip triegen.

sone merchent diu tumben wip niht, wan schone rede und schonen lip und schone gebarde dab $i$.

I30 swie valsch daz herze danne si, da gedenchent si lutzel nach. in wirt ze chofen als gach, sam die daz chopher gulden und sich selben sit schulden,

I35 do ez in brahte den schaden, der wol mit schanden was geladen. swie der man si gevar, so sol ein wip nemen war triwen, stæte und warheit.

I40 der chouf enwirt ir niemer leit, so si den man gewinnet, der si innechlichen minnet und ouch si in wol minnen mac. si solde wol den selben tac

I45 fur alle hohzit han,

I 6 ein fehlt

I 7 Versalien in Des

12 I geheizzet - ,verspricht"

I 26 betrigen

I27 Sine merkent niht die

r 28 niht fehlt

I 29 dabî $A$

I 30 sî $A$
I3 I denkent $[\mathrm{i}$ vil lvtzel. $\mathrm{t}$ in lutzel hochgestellt $A$

I37 si gevar - ,aussehe"

I 38 Eín rechtes wip die nîmt

I 40 u in chouf $\ddot{u} b e r \operatorname{dem}$ o $A$. ir hochgestellt $A$

I 43 u über dem o in ouch $A$

I 45 hochgezít 
I46 swenne ir ein man wirt undertan, der si minnet und minnen kan. swelich wip einen solhen man ane sin schulde verliuset

I50 und durch ir schulde verchiuset, der verteil ich vroude und ere beidiu hiut und iemer mere, sit man so choume vinden kan einen rehte stæten guten man.

I55 des rat ich einem wibe, der got $z u$ ir libe einen solhen man habe gegeben, daz der ir lip und ir leben iemer deste lieber $s i$

I6o und ste im sines willen bi. swa zwei herze einander sehent und beidiu nacheinander jehent, da wirt diu vroude niemer laz. ich wil noch sprechen furbaz:

I65 Ein gut man an ein gut wip, der hat et einen halben lip und enhat niht wan ein halbez leben; daz selbe reht ist ir gegeben. swa ein rehte gut man

I70 ein reht gut wip vinden chan, werdent diu einander chunt, der minne ist iemer gesunt. ist danne ir sælde so gut, daz in diu fromde niht entut,

I75 wie gar si denne einander lebent und beide ir herze einander gebent, wi vil si churtzwile hant,

\footnotetext{
I 5 verteil ich - „spreche ich ab"

I5.3 $\mathrm{u}$ in choume über dem o $A$

I 58 Daz ír ír líp. der - „Dativ fem."

I 59 sî $A$

I6o bî $A$

I63 Dane. wirt niemer laz -
}
„läßt nie nach”
I65 Versalien in Ein
172 Ir mínne. der - „Genitiv Plural des Demonstrativ- pronomens"
I74 ím die vremde; Rosenhagen konjiziert in


I78 wie si in den vrouden umbegant, wie diu liebe in ir gemuote

I80 als ein meige stet en bluote, geziret und geschonet, in allen wis gechronet, wie vaste ir triwe an ende stent als die steinwende,

I85 wie vil diu minne under in gedanche her und hin durch liebiu mære sendet, swaz diu edele art verendet, daz wizzen wol der minne kint,

I9o die daruf genaturet sint, daz si da gent ze schuole, da diu minne uf ir stuole vor den tugenden ist gesezzen. dane wirt des niht vergezzen,

I95 daz eben heizzet und sleht. diu minnechlichen lantreht, diu bechennet nie mannes lip, wan ein gut man und ein gut wip.

$178 \mathrm{Wiez}$ in

I 79 gemute $A$; gemvite $H$ 180 in blvite

I8I gekrónet

182 ge $\int$ chónet

I84 steinwænde $A$; wende $H$

I 88 verendet - „vollbringt"

I90 genaturet sint - ,geschaffen sind"
I9I schule $A$; [chviele $H$

I95 eben und sleht - ,gerade und aufrichtig"

I96 diu minnechlichen lantreht - „die gültigen Gesetze der Minne"

197 bekennet níemens lip. bechennet - „kennt, erkennt, weiß Bescheid" I98 wan - „es sei denn" 


\section{VII}

\section{Das wilde Ross}

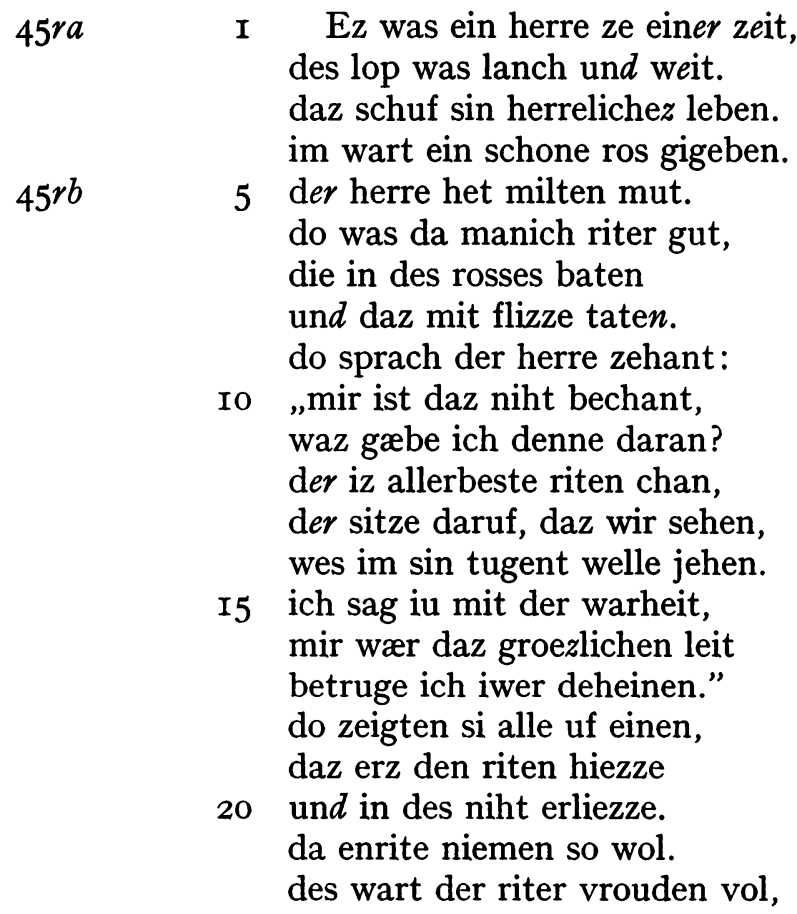

$A$ 6r. $H$ I 74

Uberschrift in $H$ :

Ditz if $t$ von vn [teten wiben

Die chvnnen vrevde $v$ Striben

I e in zeit über dem i $A$

2 e in weit über dem i $A$

3 herreliches $A$; herlichez $H$

7 die ... baten — ,die ihn darum baten, das $R o B$ reiten zu dürfen"

Io Mirn ift daz ros niht

I I waz ... daran - „warum nicht?"

12 geriten

I3 wírz

I6 $\mathrm{z}$ in groezlichen hochgestellt $A$ 
23 daz ez im ze riten geschach, wan er sich des vil wol versach,

25 ob ez im wol behagete, daz erz im niht versagete. als er daz ros $u$ berschreit und ez unverre gereit, do wart dem rosse zorne.

30 beidiu hinden und vorne sluge ez uf also sere, daz der riter niht mere daruffe beliben mohte und daruf niht entohte.

35 er viel dernider uf daz gras. als im daz geschehen was, do jahen des da genuge, er hete vil ungefuge und unmeisterlichen geriten;

40 davon het er den val erliten. der riter sprach: „die rede lat und sehet wa daz ros stat! swelich iwere ez gerite baz, daz lazze ich gar ane haz."

45 do gienge ein ander riter dar, der wart vil schire riwevar: wan man in sere vallen sach, als ouch dem ersten geschach. dem dritten geschach alsam,

50 der vierde leit die selben scham. also geschach in allen, ieslicher muse vallen, der daz ros wolde riten. darnach in churtzen ziten

24 wan ... versach - „denn er hatte sehr stark darauf gehofft"

27 aber $A$; vber $H$; siehe auch $6 \mathrm{I}, 78$. uberschreit „bestieg"

34 Noch drovffe
39 un über dem $\mathrm{m}$ in unmeisterlichen $A$

43 gerítet

44 ich gerne ane

53 wolde am Ende der Zeile mit Verweisungszeichen hinter $\operatorname{ros} A$ 
55 machet ez sich unwert, die $\sin e$ heten gegert, daz sis do niht enwolten und ez allesamt scholten.

Do sprach der herre sa ze stunt:

60 ,iu ist nu allen wol chunt des wunderlichen rosses sit.

nu betriuge ich niemen damit. nu nem ez einer, der sin ger!" do sprach dirre und der:

65 „der tivel muzzez furen hin!” do sprach der tumbest under in: „herre, wil ich daz ros han. ich han des vil guten wan, daz ez mich niht envelle."

70 „vil lieber min geselle," begunde der herre jehen, „,nu laze uns dine chunst sehen. deswar, envellet $e z$ dich danne niht, daz dir diu ere geschiht;

75 du must uns iemer allen wol deste baz gevallen." do was der riter bereit. als er daz ros uberschreit, vil vaste er sich druf bant,

80 do er des harte wol enpfant, daz ez in niht envalte, swie vil ez wunders stalte. mit den sporn er ez rurte,

55 Machte. [ich fo vnwert 56 sin fehlt $H$; Rosenhagen folgt $A$. ê $A$

58 o über dem u in schulten, wohl Korrektur des Reimes wegen. o im Präteritum tritt manchmal statt $\mathrm{u}$ ein

59 Versalien in Do

62 Ich betrevge níemen der mít

63 der ez ger

67 ich wil
72 uns chunt $A$; vn $\int$ dine chvn $\int \mathrm{t} H$

73 De [war envellet ez dich niht $H$; Diw envellet ich dich danne niht $A$

77 Des waz

79 Vil [ere

8o Daz er

8 I valte - „fallen ließ"

82 swie ... stalte - „wieviel es auch anstellte" 


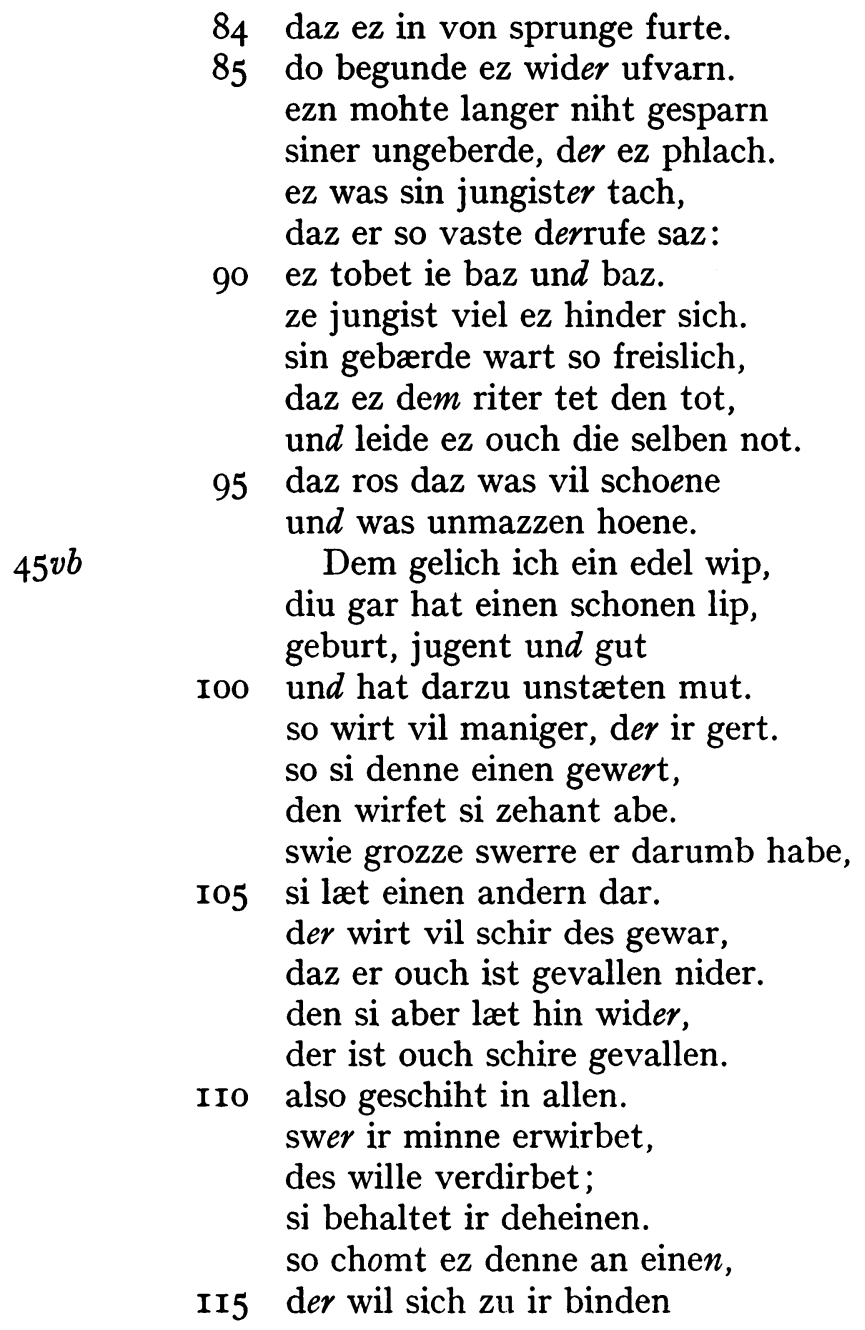

84 Do ez; Rosenhagen folgt $A$

86 Ezn wolt langer niht $\int \mathrm{pazn}$

$93 \operatorname{den} A$; $\operatorname{dem} H$

94 ovch iz.

leide-siehe Seite 16, Anm. 61

95 Ditze ros. schone $A$;

fcho̊ne $H$

97 Versalien in Dem. eín ledick

I07 ovch er

I08 dar wider

I 2 der ver dirbet

I 3 Sine behalte

I 4 o $\ddot{u} b e r$ dem $\mathrm{u}$ in chumt ist wohl Korrektur $A$

96 hoene - „böse, übermütig” 
II6 und wil des niht erwinden, er næm si zu siner $e$, er wænet des, daz ez im erge baz, denne den andern allen.

I20 der mag ir niht enphallen, daz wirt swære und leit. si mag ouch ir gwonheit durch in zebrechen noch enwil. der gwinnet si denne so vil, I25 untz si vil læsterlichen lebent und in dem tode der schanden swebent. sa ist ir beider ere tot. swie harte in mue diu not, daz er sich zu ir gebunden hat, I30 er muoz ez nemen swie ez ergat. so wirt er als tump erchant, * sam der sich uf daz ros bant.

I 6 Ern wil

I 7 ê $A$

1 I 8 Vñ wenet daz

I 20 en mag

121 ír [were

122 Síne

I 23 in niht brechen

I24 Des beget [i danne al[ vil
126 ín der [chande tode [webent

129 Zweites e in gebunden undeutlich $A$

I32 Sam der $A$ (undeutlich); Sam der [ich $H$.

* Hand auf dem linken Rand deutet auf die ersten zwei Wörter dieser Zeile 


\section{VIII}

\section{Der Hort}

$53 v a$

$53 v b$

I Ein man vant einen grozzen hort. do wande er, daz er an ein ort siner armuot chomen wære. er wart vil vroudebære

5 und lopte sin geluche, so er an islich stuche gedahte, daz darinne lach. so was er naht und tach mit ganzen vrouden geladen.

Io do gwan er so getanen schaden, daz sin sin herre wart gewar. der twanch in, daz er im gar den selben hort muse geben. davon vercherte sich sin leben.

I5 so er an de $n$ hort gedahte, daz $\operatorname{im} e$ vroude brahte, so wart sines hercen riwe so groz und also niwe, daz im lieber wære der tot,

20 denne von gedanchen solhiu not. die gedanche freuten in $e$, die taten im nu also we, daz si im alle froude namen, so si im an daz herce quamen.

$A$ 71. $H \mathbf{1 6 5}$

Uberschrift in $H$ :

Ditz i $t$ eín gvt mere gehozt

Wie eín man vant grozzen hozt

9 grozen

I I Daz ez [ín hs re
I4 Do wazt verkert [in

I5 $\mathrm{n}$ in den undeutlich $A$; $\operatorname{den} H$ I6 ê $A$

2I ê $A$. freuten "Plusquamperfekt"

24 ím ín daz 
25 Dem geschach, als einem manne geschiht, der ein schone wip gesiht, diu nach sinem wunsche ist gestalt. so dunchet in vil manichvalt diu sælde, diu in dar truch.

30 "ich han nu iemer genuch," gedenchet er, ,an dem wibe." so wirt im von ir libe mit gedanchen so wol, daz im daz herce vrouden vol

35 ze allen ziten wesen muz, swenne er gedenchet an ir gruz, an ir gebærde und an ir varwe und an ir tugende garwe. swenne er die uberdenchet,

40 so entwichet im und entwenchet sin sorge und sin swære und wirt so vroudebære, daz er des wol swuere, daz ez iemer also fuere.

45 so geschiht vil lihte ein scheiden von ir einem oder von in beiden, daz er si niemer mer gesiht und im vil lihte alsam geschiht als ienem, der de $n$ hort verlos

50 und wirt mit alle vroudelos, swenne er gedenchet an daz wip, daz er ir minnechlichen lip niemer mer gesehen sol, des wirt sin herce leides vol.

55 swie wol im $e$ davon geschach, swenne er si mit gedanchen sach,

25 Versalien in Dem. al[ noch eínẽ

26 vil [chone

27 wusche $A$; wun [che $H$

29 Sín relde

39 Vntz er

44 er ímmer. fure $A H$

46 im $A$; von ín beiden $H$

48 vil rechte ge $[$ chiht

$49 \operatorname{dem} A$; Sam ienem der den $H$. d in den undeutlich $A$ 50 Er wirt.

55 ê $A$ 
57 die gedanche marternt in nu. tumber man, daz lidest du!

$54 r a$ da git daz wip und der hort 60 an frouden einen gelichen ort. 


\section{IX}

\section{Der Gärtner}

I Ez was ein gartenære, der was vil witen mære von siner grozzen meisterschaft. sich duhte ein herre sældehaft,

5 des garten er sich underwant. sin meisterschaft was ungeschant, die wile er eines garten wielt, do er die werdicheit behielt. ich sag iu, wie er daz getet:

Io in braht miete und bet so verre von der rehten vart, daz er miteinander wart zweier herren gartenære. swie gut meister er do wære,

I5 er versumte si doch beide. daz wart ouch im leide. die garten, der er wolde gephlegen, die warn von einander gelegen wol ein grozze raste.

20 do begunde er gern vaste,

A 72. $H \mathrm{I}_{42}$

Uberschrift in $H$ :

Ditz ift ein hvb [ch mere

Von einem garthenere

I a in gartenære undeutlich $A$; gartenere $H$

2 wart

5 underwant - "besorgte"

6 vner [chãt

Nach 8 zwei Mehrverse:

$8 a$ Vntz ir den tevfel bedroz $b$ Do wazt er ir mít alle bloz

ro bet - „das, was von dem Herrn als Unterstützung erbeten wird"

I I vo in von undeutlich $A$; von $H$

I5 versuhte $A$; ver fovmte [ie beide $H$

I6 zv leîde

I 7 Dirre garten. pflegẽ

20 er fehlt $A$; er $H$. vaster $A$; vafte $H$ 
2 I daz ez im so wol ergienge, daz er bedenthalp enphienge vil grozzen lon und danch. do wart sin sælde so chranch,

25 daz sin arbeit verdarp und vient beidenthalben erwarp. der sumer beleip ane regen. swie wol er garten chunde phlegen, do wart diu hitze so groz,

30 die wile er einen garten begoz, so was daz chrut uberal in dem andern garten so val, daz im giezen chom ze spate. swie dicke und swie drate

35 er her gahte und hin durch gitechlichen gewin, daz enfrumt niht umbe ein brot. swie ofte in des chrutes not beidiu her und hin treip, 40 daz er bi einem niht beleip, des wart daz chrut gar enwiht: im enwart bedenthalben niht. do daz der eine herre sach, do sante er nach im und sprach: di ez wirs chunnen danne du, die sint so gar niht ane chrut. dun bist mir niender so trut! ervar ich, daz du schuldich bist, 50 du giltest mirz, wizze christ!"

2I Daz ím

22 in bedenthalp ein 1 eingeschoben nach $\mathrm{h} A$; beidenthalp $H$

24 So warde

25 Daz alle fín

26 Vñ ir beider vínt [chaft er warp

27 gar ane

3o Vntz er
3 I Do was

32 garten fehlt. val "vertrocknet"

37 enfrvmte. bot $A$; brot $H$; Rosenhagen sagt: das Richtige ist lot 40 bi dem eínen

47 Dinen

49 ichz daz dín [vlt i $\int t$

50 giltezt $A$ 
5 I ze jungist beleip er an der scham. der ander herre sprach alsam. den herren wart diu warheit vil rehte beiden geseit.

55 do wart im harte leide. si viengen in beide, si sprachen im an sin ere und beschatzten in so sere, daz erz niemer mer uberwant.

60 alsus wart er gephant des gutes und der werdicheit. sin schande diu wart also breit, daz man im niht getrowete me. diu schande tet im iemer we!

$65 \mathrm{Nu}$ horet ein ander mære, waz disem gartenære geliche tu. daz tut ein wip, diu einen meisterlichen lip uzzerhalp des herzen hat,

70 der allez daz ze wunsche stat, daz an ir ist wan der mut; und si doch dem geliche tut, sam ouch ir mut der beste si. da wirt si also wert $b i$,

75 daz si die sere minnent, die sich doch vil wol versinnent. swem si ir minne danne gan, der dunchent sich ein sælich man. den bringet ir libes guote

80 in also hoch gemuote, daz er des wol sw $u$ ore,

52 vor $5 \mathrm{I}$

51 in der

55 in

58 beschatzten in - „belegten ihn mit schwerer Steuer"

59 mer fehlt

66 dem. $\mathrm{r}$ in gartenære hochgestellt $A$

73 sî $A$
74 bî̀ $A$

77 gan - ,gewährt (Präteritopräsens, Inf. gunnen)"

79 guote - „Nebenform zu güete"

8o gemute $A$; gemvite $H$

8I des wol fehlt; Rosenhagen folgt $A$ 
82 der elliu lant erfuore;

er funde ein wip niht so gut.

so hat si sinen mut

85 allen wiben angesiget, die wile si eines mannes phliget.

so hat er des sin herze gert.

$s i$ ist genæme und wert,

si ist liep und mære,

90 sam der gut gartenære,

$54 v a$

des lop in guter werde lac,

die wile er eines garten phlac;

so si in der werdicheit lebet

und wider die nature strebet.

95 so lange unz sis betraget,

so entwichet si und waget

ir lop, ir ere und ir zuht

und leget sich in der schanden suht, daruz ein wip unsanfte stet.

Ioo si verhenget, daz an ir erget

eines andern mannes wille.

daz entut si nie so stille, man wirt der warheit wol gewar.

in wirt so ger beiden dar

I05 durch die liebe des wibes,

durch die suezze ir schonen libes,

daz si beginnent prinnen

von der hitze der minnen

und chumber muezzen liden.

IIo so muz si einen miden, untz si den andern gelabet

82 erfuore - „bereiste, kennenlernte"

83 Ern. niht fehlt. $\mathrm{t}$ in niht hochgestellt $A$

$84 \int i$ in linem

85 angesiget - ,abgewonnen"

$86 \mathrm{~s}$ in eines undeutlich $A$; eínes $H$

88 So $A$; Si $H$

9I ín ganzer wírde
95 betraget - „langweilt, verdrießt"

96 vraget $A$; vragen $H$; Rosenhagen konjiziert waget

99 er tet

I oo verhenget - „läßt es geschehen"

I04 in ... beiden - ,sie ergreift beide solches Verlangen (ger ist Variante von gir)" 
II2 und ir willen wol mit im gehabet.

die wile ez sich gefuget,

des in vil wol genuget,

II5 so wirt dem andern der lip

so durre, daz sich durch daz wip

verwandelent sine sine.

von dem zorne der minne

sin herze hat grozze undult,

I20 daz si in ane schult

so vremdet und beswæret.

als er ir danne bewæret,

daz si die minne beswachet

und si schuldich machet,

I25 so sprach diu tumbe chune,

daz si vil gerne sune

und biutet doch ir lougen.

so wirt ez aber tougen

gemachet zeiner friuntschaft.

I30 durch der ersten liebeschaft

geloupt er ir deste baz,

untz si im vertribet den haz.

da horet langiu wile zuo,

$e$ si der suone vil getuo,

I35 daz den andern ouch belangen muz.

da vindet si aber swachen gruz.

$54 v b$ swie dicke si si bede labe, ir beider liebe nimt abe, untz si vil gar verdirbet

I40 und si bedenthalp erwirbet,

I 2 mít dem

II5 zweites $\mathrm{n}$ in andern undeutlich $A$; andern $H$

I 8 Vom $A$; Von $H$

I 19 vngedvlt

I 20 ane fíne [vlt

I 2 I in vremdet $A$; So vremedet $H$

I 22 bewæret - ,deutlich macht"

I23 [wachet

I 24 vil [chvldick . si schuldich machet - ,ihr die Schuld dafür zuschiebt"

I 25 fprichet

I 26 suene $A$; fune $H$

127 bovtet. biutet ir lougen "sie lügt doch"

I30 liebe . kraft

I33 fo lange. zu $A H$

I 34 ê $A$

I35 u in ouch $\ddot{3} b e r$ dem o $A$

I.40 Vntz [i 
14I daz ouch der gartenære erwarp, dem sin chrut bedenthalp verdarp. des enkalt er alterseine. also tut diu unreine,

I45 diu zwein werden mannen liuget und si mit ir minne triuget. da muz si ir ere umbe geben und muz ane ere immer leben. die manne sint dannoch vrouden vol.

I50 nu weiz si daz nu vil lange wol, daz er lutzel verliuset, der ein bose wip verchiuset. ein schone wip ane ere, diu enhat niht lobes mere,

I55 wan als diu schone blume hat, diu uf einer grozen chroten stat.

I42 Dem beidenthalp fín chravt vsdazp. 1 in bedenthalp fehlt $A$

I43 enkalt - „büßte”. alterseine
_ „ganz allein" I 46 mit mínnen

I47 si fehlt

I 50 Man weiz daz 


\section{$\mathrm{X}$}

\section{Frauenleben und Pfaffenleben}

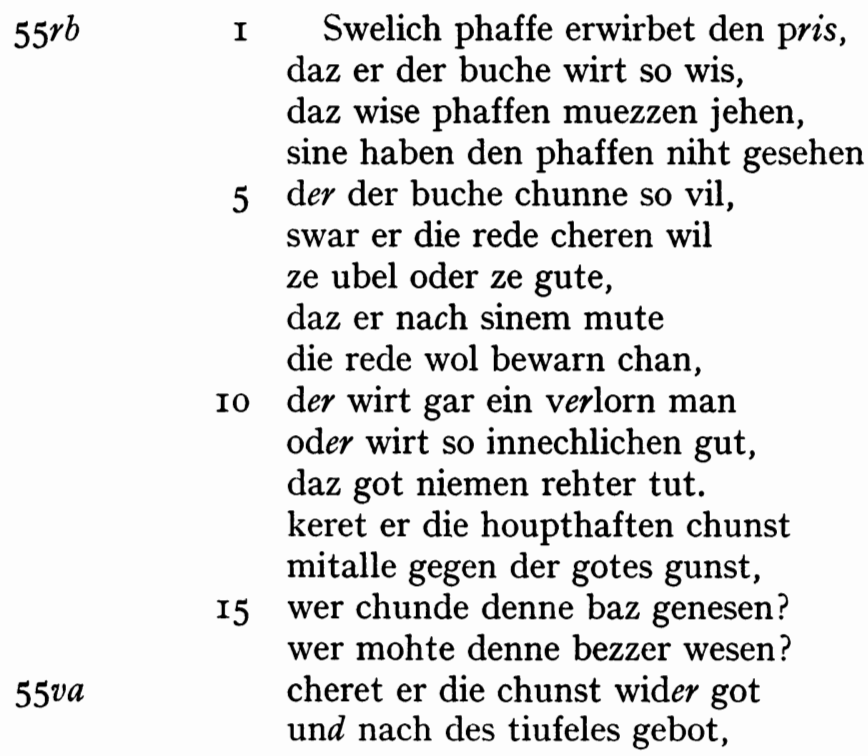

$A$ 74. $H$ I62 a

Vor $H \mathrm{r} 62$ a steht zuerst ein

8-zeiliges Lehrgedicht (E Tel. govch . vin . affen) und daran im Anschlu $\beta$, ohne Versalien oder Absatz, die Zeilen:

$H$ I Swer got wil minnen

2 Der mag wol [elde gewínnen

3 Swer vil wil ligen

4 Den fol man gerne betrigen

5 Swer $\int$ pil wil minnen

6 Der mag vn felde gewínnen

7 Man 〔ol wín nízzen
8 Des wil mich deín bedríezzen

9 Schoner lip gvter

Io Mít zvchten reíne gemvter

I I Minne mich vrowe

I Daz dich die [elde be [chowe

$A$ I-38 fehlen in $H$

I $\mathrm{r}$ fehlt in pris, i ist hochgestellt $A$

2 buche - "Heilige Schrift"

$8 \mathrm{c}$ in nach hochgestellt $A$

I4 gegen der gotes gunst „Gott zu” 
I9 sone chan im niemen widersten.

20 des muz sin wille fur sich gen.

so wirt er ouch der wirste man, $\mathrm{d} e r$ ie von muter lip gewan.

Dem geliche ich eine vrowen, diu gesprechen und schowen

25 mac offenbar und tougen ane hut und ane lougen ze allen ziten, swenne si wil und sihet der liute unmazzen vil, der chunden und der geste,

30 daz wirt diu aller beste, diu iender hat vrowen lip oder wirt daz aller boeste wip, diu in der vrowen namen hat. ob si den allen widerstat,

35 die durch ir schone und durch ir gut und ouch durch ir hohen mut werbent umbe ir minne, so hat si starche sinne. sit man daz niemen understet,

40 swer zu ir sitzet oder get, und sit vil liute bi ir ist, mach si denne ir deheines list niemer me verschunden ze schanden noch ze sunden

45 und belibet gar unmeilich, so ist si benamen heilich. wirt si aber ane scham, so machet si der vrowe nam, ir geburt, ir schone und ir jugent,

50 ir gute und ir untugent $\mathrm{zu}$ dem aller boesten wibe.

22 iê $A$

29 chunt - "bekannt"

30 Abbreviatur nebst er in aller $A$

39 Sit male daz. Úbergang in $H$ erfolgt ohne Versalien oder
Absatz. staet $A$

$40 \mathrm{zV}$ zít [itzet oder [tet. gêt $A$

43 verschunden - ,verführen". mê $A$

45 unmeilich - ,makellos” 
52 so get $\mathrm{zu}$ ir einem libe

vil strazze die man gerne vert

und si vil vlizechlichen bert.

55 man suchet die durch ir gut mere, denne man die armen tut. so cheret man durch ir edel dar, des nement gnuge liute war. so chumt ir durch ir schone vil.

60 diu schone ist tumber liute spil, da man si vindet ane tugent.

so chumt vil maniger durch ir jugent. so chumt ir vil durch den gelust, den si da tragent in der brust.

65 die strazze sint vil manichvalt, daz ir diu bosheit mit gewalt an allen enden nahet und ir zu mit schalle gahet, daz si muz bose beliben

70 vor allen boesen wiben. swelich vrowe belibet unbehut und daz bi vil liuten tut, diu wirt der besten eine oder si wirt so unreine,

75 daz ir deheiniu chan gelichen. si muzzen ir alle entwichen, ode si entwichet aber in allen. si chan niemen uberschallen. des gelichet si dem phaffen,

80 umbe den ist so geschaffen, daz er der buche mer chan denne in der werlt dehein man. der wirt bezzer denne die guten sint ode wirser denne des tievels kint.

85 sus ist dem phaffen gegeben und der vrowen ein gelichez leben.

52 ir fehlt. einer $A$; eine $H$; Rosenhagen konjiziert einem

53 [trazen die. ie in die undeutlich $A$

55 [i dvrch

6 I Daz man
65 fo manícvalt

73 Daz wirt

74 si fehlt

78 Sine

80 den íz fo i $[\mathrm{t}$

86 geliches $A H$ 


\section{XI}

\section{Ehemanns Rat}

$67 r a$

I Als ich mich versinnen chan, so hilfet ez dehein man wider sin tumbez wip, daz nim ich uf minen lip,

5 swie vil er frumcheit hat, denne als ez an sinen selden stat. $\mathrm{ez}$ ist manich piderber man, dem al diu werlt guotes gan; im wirt sin wip doch nimmer holt,

Io gæb er ir aller chriechen golt, ezn hilfet in niht, swie wert er si. so ist ein ander wip dabi, diu einen so bosen man hat, daz er nimmer niht des begat,

I5 wan darumbe man in schiltet, und er des engiltet nimmer niht wider sin wip, ern si ir liep sam der lip. e si von dem bosen quæme

20 und einen biderben næme, si gienge $e$ mit im bitten brot. so ist aber diz ein ander not, daz einiu zwene man hat

$A$ 95. $H$ II 7

Uberschrift in $H$ :

Ditz i $\mathrm{t}$ wie eín man geníezẽ kan

Síner frvmkeit wids fín wip níht

3 vil tvmbes

8 Dem vil der wíbes gutes. gan -- „Präteritopräsens"
9 doch fehlt

I I Iz enhvlf. niht fehlt

I6 niht engildet

I 7 niht fehlt

I 8 fam ír lip

20 vil bíderben

2 I e biten mít ím brot. ê $A$ 


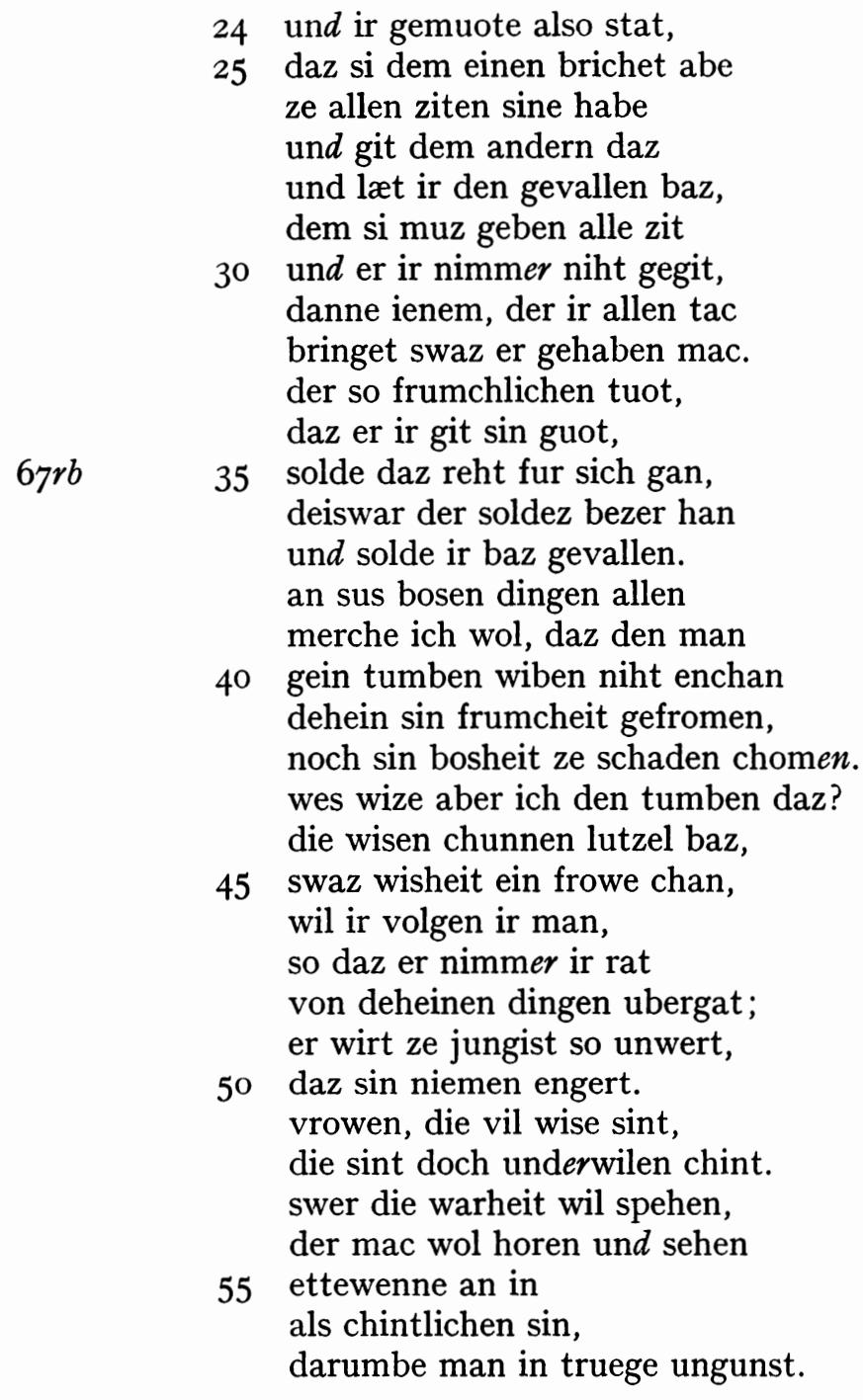

30 Vnd ír. engît

3 I Dem der; Rosenhagen

konjiziert denne den

32 haben

34 er gibt; Rosenhagen folgt $A$

38 An den boe $\int e n$

4I iht gefrvmen

48 An keínen díngen

54 vñ iehen

57 im; Rosenhagen folgt $A$ 


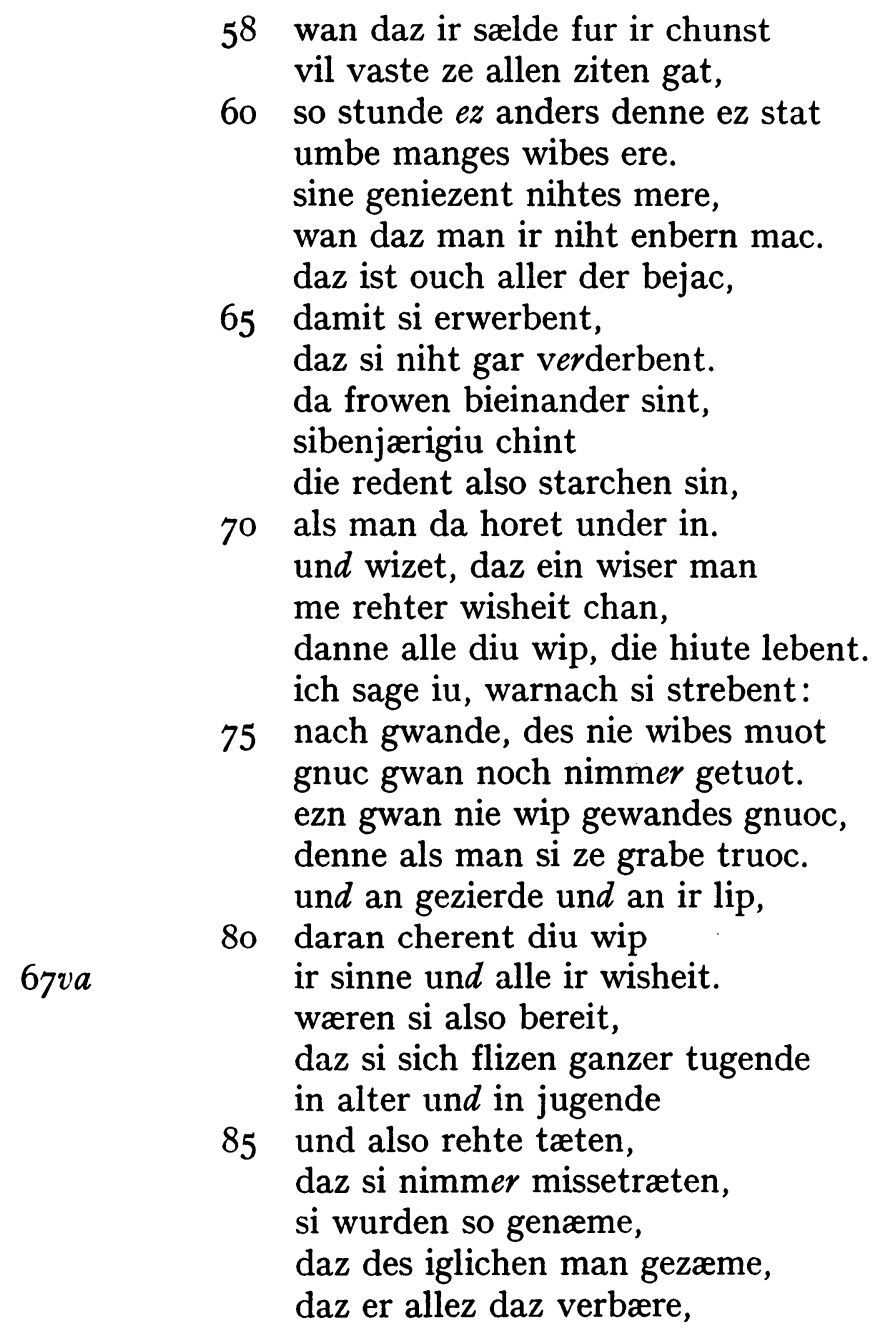

$5^{8}$ vor

60 ez fehlt $A$; iz $H$

62 ne fehlt

63 daz und ir fehlen; Rosenhagen konjiziert wan man ir

64 bejac - „Erwerb”

76 getut $A$; tvt $H$

79 und fehlt vor an ir

$8 \mathrm{I}$ alle fehlt

75-84 werden in $H$ wiederholt. Außer diakritischen Abweichungen nur im folgenden anders: [i zv statt [i ze (78). cherent statt kerent $(80)$ 
90 daz wider ir hulden wære. ir sælde wurde so groz, daz si der engel genoz an werdicheite wæren, ob si allen valsch verbæren.

95 Ein man hat nie so frumen lip, ezen dunche doch sin wip, daz ein ander tiwerr si. des wænet si liht uf dri, die allesamt boser sint.

Ioo da merchet an ein chlein chint, swer dem einen phenninch git, als ez in ein churze zit harte wol getriutet, der im ein e $i$ biutet,

I05 ez git den phenninch umbe ein ei. daz sint gelicher dinge zwei. swelch frowe choufen solde reht allez, daz si wolde, und entsæze niemans haz,

I IO si choufte ettewenne daz, daz wære ein als unnutze dinc als ein ei umbe einen phenninc. ezn ist der frowen reht niht, daz man der dinge immer iht

II5 von ir werchen verneme, daz in von schulden missezeme. si solten sich behuten wol. næme manz dannoch fur vol, des mohten si wol wesen fro.

I20 ez stet umbe die frowen so, swiez dem man niht nahen ge, daz man ir engiltet michels me, denne man ir immer genieze. daz die man des iht bedrieze, I25 daz solten si verschulden 


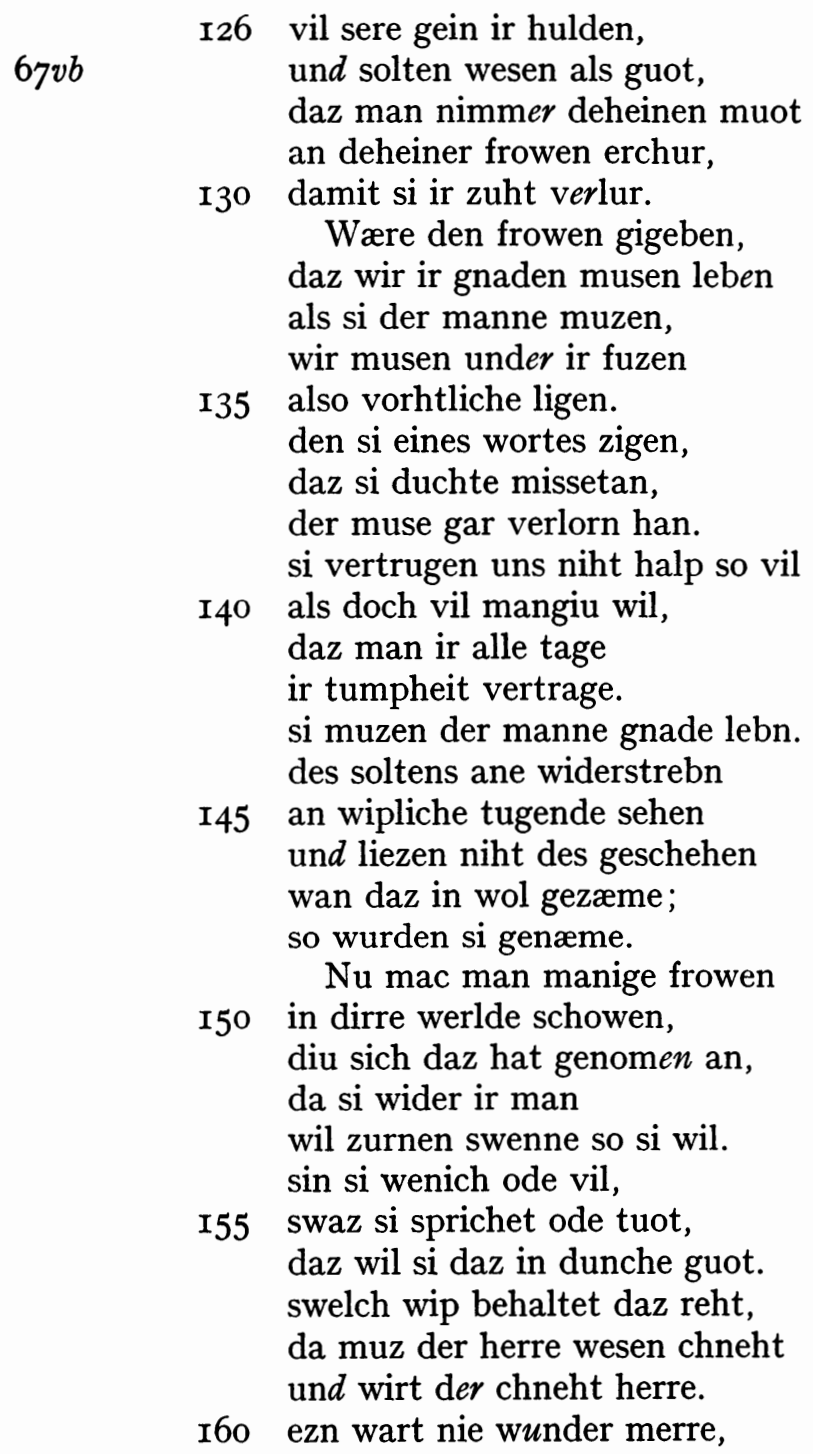

123 genevzzet

I24 des níht bedrevzzet

I29 deheinen; Rosenhagen folgt $A$

I32 lebn $A$; leben $H$
I 39 niht als vil

I47 im; Rosenhagen folgt $A$

I 53 [wen rie

I54 Iz Iei

\section{4}


I6I so, daz die habent so groz heil, daz man ir niht ein michel teil ze tode darumbe erslagen hat. der einen kunige widerstat,

I65 dem nimt ein wip sin ere. ez schadet den mannen sere, daz si tumben wiben sint ze guot. ezn gwan nie schaf so zamen muot, ezn werde ze jungist wilde,

I7o der ez an dem gevilde ane huote lat die lenge. ezn wart nie ros so genge,

$68 r a$ wil manz ze allen ziten ungezoumet riten,

I75 ane gerten und ane sporn, elliu sin tugent si verlorn. ich nim ez uf minen lip, daz lutzel lebt dehein wip, der so liep si ir man,

I8o bræhte si in daran, daz er allez daz lieze, daz si in lazen hieze und anders niht tæe, wan des si willen hæte,

I85 er wurde ir so unmære, daz si sin gerne enbære und het in wirs dann einen chneht. ezn ist gewonlich noch reht, daz ein man sin wip so minne, I9o daz er aller siner sinne vergeze durch ir liebe. si wirt ez zeinem diebe und hat den man fur einen gouch; niht baz erbiutet siz im ouch.

I95 Ez ist so verre uzchomen,

167 [o gv̂t

I68 iz statt ezn

I 76 frvmekeit 183 entete
I89 eín wíp

I92 es $A$; iz $H$

I94 enbevtet $[\mathrm{i} \mathrm{imz}$

I95 Versalien in Iz 
I96 daz man vil wol hat vernomen, swelch man sin reht also verbirt, daz sin wip sin meister wirt, so tut si nach der selben frist

200 vil mangez, daz im leit ist, daz si vil gar verbære, ob er ir meister wære. swa daz wip ze meister wirt erchorn, da hant si ir ere verlorn

205 beide daz wip und der man. da suln die gedenchen an die mit eren wellen beliben, und suln niht tumben wiben an allen dingen volgen.

210 swelch wip mir ist erbolgen durch disen rat, diu tut wol schin, daz si ir mannes meister wil sin. 


\section{XII}

\section{Die Minnesänger}

I2Ira

$\mathrm{I} 2 \mathrm{I} r b$

I Hie vor do man die huote schalt und des sumlich wirt sere engalt, daz er lie sin husfrowen die geste gerne schowen,

5 do si ir triwe ubersach und ir reht und ir $e$ zebrach, daz hiez hohgemutiu minne. hete sumlich wirt die sinne, daz erz mit huote understuont,

Io als noch die wisen gern tuont, den begunde man do schelten und liez in des engelten, daz er was ein merchære, daz er toup und blint wære,

I5 des wunschte man im lange mit rede und mit gesange. do si also toren suohten, die des an die frowen geruohten, daz si ir triwe verchurn

20 und gotes hulde verlurn, do chom manic gast an die stat, da in ein wirt ze huse bat

$A$ I 55 a. $B$ 42. E 56. I 39

Uberschrift in $B$ 42: Aín mer von $\mathrm{d}^{\mathrm{S}}$ ka ẅllerín. Keine UberschriftinI.

$A$ I-59 fehlen in $E$ (siehe Bemerkung in der Einleitung)

I huote - "Bewachung". schalt - "tadelte"

2 Des manig wirt enkalt $B I$

3 frawñ $B I$
5 Daz fi $B I$. ubersach "gering achtete"

6 Vñ auch ír ee $B I$. ê $A$

7 Durh gemut mínne $B I$

8 Doh het etleichs wirt $B I$

I I man darumb [cheltñ $B I$

I4 tumb $B I$

I 8 ruchtñ $B I$. geruohten „begehrten" 
23 und in $\mathrm{zu}$ der frowen sitzen hiez und in churzwile haben liez.

$25 \mathrm{~d} e r$ wirt gie wider und fuer fur sin tor und fur sin tuer und schuof da swaz er wolde und swaz er schaffen solde, die wile er schuf umbe den gast,

$30 \mathrm{daz}$ im da nihtes gebrast. die wile warp er umbe daz wip und leidet ir des wirtes lip. do was ir zweier gerinc jedoch ein ungelichez dinc:

35 der wirt fleiz sich vil sere, daz er gemach und ere sinem gaste da gefueget. so belouc er und rueget den wirt so sere wider sin wip,

40 daz si noch gern sinen lip vil schier toten het gesehen, danne im iht baz wære geschehen. sus huob er an und sprach: „frowe, mir ist daz ungemach,

45 daz ir unz her an dise zit der frouden vil gesoumet sit, der ir wol wert wæret. ir habt mich vil beswæret, daz iwer tugent davon zergant,

50 daz si der minne niht enhant, diu billich swaimen solte in frouden swa si wolte. ir habt leider einen man, der der minne suezze niht enchan

25 fuor $A$ 30 da fehlt $B I$

3 I vmbs $B I$

34 Doch $B I$

35 vil fehlt $B I$

37 da fehlt $B I$. gefugte $B I$

38 So vslait er vñ v $v^{\text {stugte }} B I$
40 noch fehlt $B I$

43 Do $B I$

44 Awe $B I$. dz ain vngemah $B I$

$4^{8} \mathrm{Ez}$ hat mích $B I$

5 I swaimen - „schweben"

53 Ir Majuskel $B$

54 Der ze mínne nícht $B I$ 
55 gemachen so manichfalt, daz sich ieslich tugent mit gwalt $\mathrm{zu}$ der froude also gesinde, daz man si stæte vinde in der hohe des muotes.

60 so suze und so guotes des enwart nie niht, noch nimmer tuot so liep, so edel, so guot, so diu hohe tougen minne. da ist so groze chraft inne,

65 daz si durch die minne strichet und die tugent alle richet. si edelt die gebære, si vertribet alle swære, si chan den gedanchen ere geben,

70 si tiuret den lip und daz leben, si ist der selden vorlouf, si git an frouden guten chouf, si læt gedenchen swes man wil, und git wol vierstunt als vil,

75 si chan den man zieren und daz herce furrieren mit niwen frouden alle zit. welt ir der richeit, die si git, einen ganzen hort gewinnen,

80 so ruchet mich, frowe, minnen. ich wil durch iuch wunder began, des ir immer frum muzet han. ich mac niht als ich solte

55 und 56 fehlen $B I$

57 nach 58 BI

57 Noh ze frä̈dñ fich gefind $B I$

6o noch [o guts $B E I$; gutes $A$

61 en fehlt $B E I$

62 noch fo gut $B E I$

63 div werd mínne $B E I$

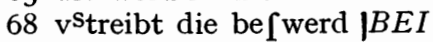

69 kan gedenkn $B I$. den fehlt $E$

70 tewret leib vnd lebñ $B E I$

7 I vorlouf - „Vorläufer (das, was beim Keltern zuerst kommt)"

72 geit frä̈dñ reich kawf $B I$. git den frauwen $E$

74 wol tehlt $B I$

76 furrieren - „überziehen”

78 die $A ; d^{\mathrm{S}}$ reichait $B I$

8 o gerucht $B E I$

8 I wunds durh ew $B I$

82 Der ir $B$. frawd $B I$. Daz ir imms fraude $E$. frum „Nutzen” 
84 gereden und als ich wolte.

85 ich sage iu, wavon daz geschiht: ich enhan der stæte leider niht. des saget mir schier iwern muot, und minnet mich, ez wirt so guot, daz ir die zit, swenne ez ergat,

90 fur alle hohzit immer hat. irn muget sus niht lange leben, iu ist mit iwerm manne vergeben. ich mache iu hohgemuetiu jar, ich mache iuch lieht und chlar

95 iwer herce als einer gimmen glast, ich mache iuch alles leide gast. swenne ich in der minne hoehe iwer tugent gar gefloehe, da zeige ich iu der selden funt $\mathrm{I} 2 \mathrm{I} v b$

roo und mache iu solich sueze chunt, diu alle suze ubersuzet, diu daz herce so sere gruzet, daz ez alle sorgen fliuhet und sich in die hohe ziuhet,

I05 die diu minne bowet und ir chint, da si immer unerstigen sint." daz æffen und daz triegen, daz chlaffen und daz liegen, daz næme ein bose wip fur guot

IIo und sagt danne ir bosen muot

86 en fehlt BEI

$88 \mathrm{Daz}$ wirt ew nütz vnd gut $B E I$

89 und 90 fehlen $B E$

9I n fehlt nach Ir BEI. fust nit lenger $E$

92 vergebn $A$

94 Vnd mach $B E I$

95 hertz zu aine $B E I$. einer gimmen glast - „den Glanz eines Juwels"

96 ich ... gast - ,ich beraube euch allen Leides"
98 gefloehe - „in Sicherheit bringe"

97-IO2 fehlen BEI

103 Daz ír all forg BEI

I04 Vnd ew in fraẅd ziehet $B E$ I

I05 Div wunn pawt $B E I$

Io6 Vnd ÿmms vnusdorbñ fínt $B I$

I09 Daz ret aín pö $\int e r$ man vs gut $B I$

I Io Vnd $\mathrm{p}^{\mathrm{s}}$ ngt der frawn pö[n mut $B I$; mut $A$ 
II I ir ungetriwen ratgeben, die ouch nach schanden chunnen leben, die chunnen ir daz wol raten, daz si selbe gerne taten.

II5 Swelch frowe hat einen valschen lip, diu wil bi ir han ein valschez wip, ob sis immer behalten chan, diu ist der frowen Salman, diu chreftiget si und stætet,

I20 si fuget ir und rætet. wie hofsch ir muter wære, wie si tanzen nie verbære, si chunde wol froude machen! si sagt ir von den sachen,

I25 da si ir frowen mit betoeret. swaz ze guten dingen hoeret, des wirt ir munt nimmer lut. des ist si gar ein frowen trut. dawider chan ich wol den rat,

I30 der solhen dingen widerstat: swelch ritter hat ein valschez wip, diu beidiu, ir ere und ir lip, unreinet und uneret, der si von mir geleret,

I35 alliu wip, diu bi ir sint, si sin alt oder chint, daz er die slahe alle tage und in daz wærlichen sage, si sin im ane triwe

I I Versalien in Ir BI. r in ungetriwen hochgestellt $A$

I 12 ouch fehlt $B I$

II3 Die konden $E$

I 6 bi ir fehlt $B I$. v und hochgestelltes $\mathrm{v}$ in wil $A$

II7 [is indert gehabñ kan $B E I$

I 8 [aloman $B E I$

I20 ir fehlt $B I$

Nach 120 zwei Mehrverse in BEI

I $20 a$ Vnrechte frä̈d wa [i mag $b$ Si let ír nacht vnd tag

I 2 I hüb [ch $B I$. müt $I$

I25 Da mit man frawen töret $B I$; Do man (Rest wie B) $E$

I26 Daz $B E I$. ghöret $B I$; horet $A$

127 wirt mũt nímm 3 . lût $A$ I 29 ain rat $B I$. Da Majuskel $B I$ I3I man $B I$. ain folhs weib $B I$ 132 Div ir fel vnd iren leib $B E I$ I35 All div weib $B E I$ 
I40 und machen im solich riwe, daz im lieber wær der tot, danne diu groze tæglich not. so sprechent si spat und fruo ir vrowen weinende zuo:

I45 „wir enmugen niht bi iu genesen, irn wellet danne rehte wesen.

$\mathrm{I} 22 \mathrm{ra}$ unser herre ist uns durch iuch gehaz. nu gelernet ouch an uns daz, swie schier er uns erslagen hat,

I50 daz ez danne uber iuch selben gat. so geschiht iu, als uns ist geschehen. ir mugt wol horen und sehen, er ist mit dem tivel behaft, $\mathrm{nu}$ furhtet sine meisterschaft

I55 und volget unserm rate ode ir furhtet in ze spate." so man die selben warheit ze allen ziten vor ir seit und si wol horet alle tage

I60 vil groze unfroude und chlage und dehein froude horet, daz zefuret und zestoret ir unget $r$ wen ubermuot, swie ungerne siz tuot,*

I4 I ín $B E I$

I 42 groze fehlt $B E I$

145 en fehlt $B E I$

I46 n fehlt $B E I$

I 48 lerñt $B E I$. von vns $E$

I 49 Als $B E I$

I50 ergat $E$

I 5 V $\tilde{n}$ ge [chiht $B E I$

I 54 vor I53 BEI

I 53 Er hat zorns $\ddot{v b r}$ kraft $B E I$

I 54 Vnd ift $B E I$

I $55 \mathrm{Nu} B E I$

I 56 furhet $A$; fürcht $B E I$

I 8 Ir ze allñ zeitñ vor $[$ ait $B I$

I6o Vil fehlt $B E I$
162 Vnd zerfürt $B I$

I63 ubermut $A$. $\mathrm{r}$ in ungetriwen hochgestellt $A$

Nach 164 vier Mehrverse BEI.

*Diese Mehrverse machen $A$ I65 ff erst verständlich: in in 165 bezieht sich auf $164 c$ : leo

I64 $a$ Div forcht vñ de [tet rat $b$ Macht $\mathrm{d} z$ [i div tumphait lat. Machent $E$ $c$ Ain leo hat vorcht dar zu $d$ Wíe ez im doch nicht we tu 
I65 daz man i $m$ bliwet vor den bern. ez muz ouch eine frowen swern, daz man ir bliwet vor ir wip, daz leidet ir leben und lip. swelch man sin wip des erlat,

I70 daz si der vor ir niht enhat, die ir raten ode die si leren wider ir triwe ode wider ir eren, $\mathrm{d} e r$ sol ouch daz gern understan, daz die werbær zu ir gan,

I75 die der hofschære boten sint und dem tivel merent siniu chint. dar nimmer, weder wip, noch man, mit botschefte chomen chan, dar chumt ein unholde

I80 mit silber oder mit golde, diu sol ein furchoufærinne sin. gutiu hæftel und gutiu vingerlin, diu treit si veile an ir hant, si treit risen und chramgwant

I85 und twehel und tischlachen, damit chan si machen,

I64 c-I65 Siehe Deutsches

Sprichwörter-Lexikon, II, hsg.

Karl Friedrich Wilhelm

Wander, Leipzig, 1870, S. 883:

„,Den Hund vorm Löwen schlagen-Einen Schwächern in Gegenwart eines Mächtigern bestrafen, damit dieser sich eine Lehre darausziehe. Etwa wie: Den Sack schlagen und den Esel meinen;" oder auch in einem anderen Strikkerbisspel ( $A$ I49, Bib. A, 24, $\mathrm{S}$. I93): er bliuwet für si ir selber kint

also man ze maneger stunt für den lewen tuot den hunt I65 für den $B I$; foz dem $E$; in $A B E I$

I 66 be $\left[w^{\text {sn }} B I\right.$

I67 w in wip undeutlich $A$; wip $E$. ir vorbliwt ir weib $B I$

$168 \mathrm{Ez} B E I$

I 70 〔 i niẽ̃ vor ír hat $B I$

I 7 I ratñ vnd $\int$ ei $B E I$

I 72 vnd statt ode $B E I$

I73 [ol ir gerñ $B E I$. u in ouch ïber dem o $A$

I74 ir werbs $B E I$. nícht gan $B E$; nit $z \ddot{w}$ Ir gan $I$

I 76 tiefel nerñt $B E I$

177 nimmer fehlt $B I$

I 80 vnd statt oder $I$

I82 Heftel oder víngerleín $B E I$

183 Diu fehlt $B E I$. der hant $B E I$

I84 Dar zu rei[̃̃ vñ gwant $B I$;

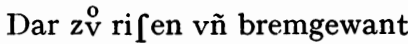
E. risen - „Schleier"

I85 Tweheln vnd tiflachñ $B E I$. ,und Handtücher und Tischtücher" 
I87 daz man si zu der frowen lat. so si da, swaz si veiles hat, die lute læzet schowen,

I90 so wirt si mit der frowen vil tougenlichen redhaft und wirbet solhe botschaft, der der wirt vil gern enbære. west er diu rehten mære,

I95 er wurde darumbe zornvar. so git si ir einen brief dar, den liset daz vil tumbe wip so dicke, unz daz si ir selber lip einem andern man erworben hat.

$200 \mathrm{ez}$ ist ein groziu meintat, darnach die tivelinne jagent, die solhen chouf den frowen tragent. ez sint verraterinne, die der triwelosen minne

205 vil fugent durch die miete. der die selben so beschriete, daz si niht luste ze leben, daz læge vil wol und eben. swelch frowe daz niht hat fur guot,

2IO ob si ir man hat wol behuot, diu enist niht der besten eine. ein vil rehtiu und ein vil reine, diu nimt die huot fur vol, ir tut daz in ir hercen wol, 2I5 daz si beziuget mit ir man,

I88 Swaz [i dann vails $B I ;$ Daz [ie deñe veiles $E$

I89 Daz lat $\int i$ di laẅt [chawn $B I$; Lat die lüte fchauwen $E$

193 vil fehlt $B I$. Des der $B E I$

I 95 vil zorn $E$

$196 \mathrm{Si}$ geit ír $B E I$

197 Dan li [et $B$. vil fehlt $B I$

I98 vntz $\int i$ den leib $B I$; hintz daz [ie den líp $E$
199 man fehlt $B I$

200 mi [ $\int$ etat $B I$

203 und 204 fehlen BEI

205 Vnd füegent durh míet $B I$; Vñ fügent $E$

206 beschriete - „,ins Gerede brächte"

208 Daz leb vil $B$

2 I I en fehlt $B E I$. ein $A$ $2 \mathrm{I} 2$ vil fehlt 2 mal $B E I$

64 
216 daz si niemen niht gezihen chan. swelch wip wil valsch vermiden, die mac wol hute liden. swelch frowe ir eren hueten wil,

220 die enduhte der huete niht ze vil, die ir al die lute baren, die in der werlde wæren.

$A$ I55 $b \quad$ Swelch gast daz hat fur hofscheit, ob einem wirt ein herceleit

225 von sinem hofschen libe geschæhe an sinem wibe, dawider wære ouch daz vil sleht, tate der wirt dem gaste sin reht und erzeiget im diu mære,

230 wes sin hofscheit wert wære. swenne er da ze tische sæzze und gern trunch und æzze, so wære daz vil gefuege, daz man fur in truege

235 edel bluomen, loup und gras, daz ie der hofschære vroude was; und einen vogel, der wol sunge, und einen brunnen, der da sprunge under einer schonen linden,

216 niht fehlt BI. gezihen "beschuldigen". niemen "Nominativ"

217 fal $[\mathrm{ch}$ wil $\mathrm{v}$ smiden $E$; valsh $A$

2 I 8 zucht $I$

220 end unket $E$; dunkt $B I$. niht fehlt $B$

$22 \mathrm{Ob}$ all die ir hut perñ $B I$;

$\mathrm{Ob}$ ir alle die hüte $E$. baren $A$

Nach 22 I zwei Mehvverse BI

22 I $a$ Hie endt fich $\mathrm{dz}$ mer

$b$ Got fei vn [er hüter

$A$ I $55 b . B$ 61. E 57. I 56

Uberschrift in $B$ 61: Von des ga ts hofzuft

Uberschrift in E 57: Von

hof [chern

Uberschrift in I 56: Von des

ga ts hoffzucht

223 hüb [hait $B I$. hat - "hält"

225 hüb[chñ $B I$

226 Gefchiht $B E I$

227 ouch fehlt BI

230 hüb $\int \mathrm{chñ} ; \operatorname{hof} \int \mathrm{chen} E$;

hüb [chait $I$

23 I da fehlt BEI

234 man da für $B E$

235 Edel fehlt BEI

236 hüb[chñ $B I$

$238 \mathrm{~d}^{\mathrm{S}}$ wol $\int$ prũg $B E I$ 
240 so moht er wol bevinden, wie grozze froude ez allez git, davon er singet alle zit. ern næme niht ein gruz, daz er chumbost oder gabuz

245 an sinem sange nante ode solich ungefuge erchante; und næm ez danne in den munt, daz wære noch boser tusent stunt. man solz an blumen cheren.

$25^{\circ}$ also solt ein wirt eren einen hofschen gast mit spise, so wurt er so wise, daz er weste diu mære, waz er wurbe oder wer er wære.

255 chome der gast in der frist, so der blumen zit niht enist, so solt der wirt sprechen: ,ir welt iwer hofscheit brechen, daz ir nu suchet deheinen wirt,

260 die wil man der bluomen enbirt. ir sult niht wan der bluomen leben: die mag iu niemen nu gigeben. des sult ir nu verborgen sin, sam diu wol singenden vogelin,

265 und sult chomen in der zit, diu loup und grune gras git. ez ist ein grozziu unmazze, daz ir ritet sam die frazze

24 I allez fehlt $B I$

243 Er nem $B E I$. ein gruz „ein Korn (hier: das Geringste)"

$244 \operatorname{der} A$; kumbu $\int \mathrm{t}$ oder $B E I$. chumbost - „Eingemachtes, meistens Sauerkraut". gabuz - „Weißkohl”

245 erkand $B E I$

246 Vnd fülh vnfvg nand $B E I$

247 Vñ izzet ez dan in munt $B I$; in den munt (Rest wie $B$ ) $E$
248 Daz i[t pö [er taw [ñt $B I$

249 [ol fich $B E I$

25I Sein hofleichñ $B I$; Sinen $E$

254 od $A$; er würd od $B I$. wær $A$; waz er wer $E$

255 kumt $E$. zu der $B E I$

256 en fehlt $B E I$

258 hub [chait $B I$

$259 \mathrm{nu}$ fehlt BEI

262 nu fehlt $B I$. gebñ $B I$

267 grozziu fehlt $B I$ 
269 in deheinen hof, da chue stant

270 und diu swin ir cherren niht lant.

man sol den hofschær vinden

bi dem walde und bi der linden,

da solt ein hofschær stæt sin, und hieze ein chleinez vogelin

275 siner vrowen sagen diu mære, daz ir niemen holder wære, er solde siner vrowen

bi dem walde und bi der owen in dem vogelsange biten.

280 er solt niht neisen riten in islichen chuestal. ein sou und ein nahtegal die singent ungelichen sanc. ein hofschær ist gar ze chranc, I22vb $285 \mathrm{der}$ sin selbes so vergizzet, daz er einen rinderinen prate izzet. ein hofschær solde selbander an einem jungen galander ein wochen haben wirtschaft. 290 hat sin minne so ganze chraft, im machet einer lerchen fuoz eines grozen hungers wol buoz." swelch wirt so biderbe wære, daz er einem hofschære

269 In den hof $B I$

27 I hüb $\left[\mathrm{ch}^{\mathrm{s}} B I\right.$

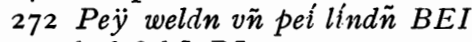

273 hub $^{2} \mathrm{ch}^{5} B I$

274 hiez EI

276 er $B I$

278 vor $277 B E I$

277 In dem wald vñ in den awñ $B E I$

278 Dann (eins liebñ frawñ $B I$; er fíner (sonst wie $B$ ) $E$

279 Su ft [ol er lebñ ze allñ zeitñ $B E I$

280 na [chen $E$. fol $B E I$. neisen - „bedrängen,

plagen"

281 yegleichen $B E I$

283 Habñt vngelaichñ $B I$

284 Ain hüb [chr $B I$. gar fehlt $B I$

285 Der [ich al [o vergizzet $B I$

286 rinds pratñ $B E I$. rinderin "vom Rinde"

287 Ain hüb $\left[\mathrm{ch}^{\mathrm{S}} B I\right.$. [ol BEI

288 jungen fehlt $B E I$. galander -

"Haubenlerche"

290 div mínne gantz $B E I$

292 wol fehlt BEI

294 Daz aín hüb [cher $B I$ 
295 siner hofsheit chunde lonen, des begunde der hofschær schonen und ensuht in niht an toren stat; er wurde der blumen so sat, swenners in zeinem male het gigeben,

300 swie lange si beide solten leben, daz er si da niht mere suhte und sines wibes niht enruhte. swelch minnær also minnet, daz im von minne brinnet

305 sin herce in sinem libe nach eines andern mannes wibe, $\mathrm{der}$ hat der hitze gar ce vil. swer im darzu geben wil guoten pfeffer und guoten win,

3 Io so muz im deste heizzer sin. swer im wil lengen sin leben, der sol im chaltez wazzer geben, daz chan der hitze widerstan. diuselbe hitze ist so getan,

3I5 si chumt von dem hellefiure und von des ubelen tivels stiure. da sol ein wirt merchen bi, waz einem hofschær gut si. sit im ze heizze doch geschiht,

320 so mere im sine hitze niht. diu spise, damit er mac genesen, diu sol in chalter wise wesen, diu die hitze so wol entrenne, daz si in niht gar verbrenne.

295 hï [chait $B I$.

Abbreviaturzeichen nach chund $A$; kund $B E I$

296 ain hüb [her $B I$; ein $E$

297 en fehlt $E$

299 Het er ims aín mal gebñ $B I$; Swenne er imz $E$. gigebn $A$ 301 er in nícht $B I$; er lin niht $E$ 302 Noch [eíns weibs enruchte $B I$; Noch fines $E$

303 Swer noch alfo $B I ; \mathrm{Sw}^{\mathrm{S}}$ imms al fo $E$

3I I Der ím lengñ wil 〔ein $B E I$

312 der mu $[z I$

3 I 5 fiwer $A$

316 v̈bln gaifts [tewr $B E I$

3 I 8 hüb $\left[h^{\mathrm{S}} B I\right.$

319 Seit im doch fo haiz $B I$; ze (sonst wie $B$ ) $E$; i in heizze undeutlich $A$

32 I Div (pei [e der er mag $B I$;

Der [pi [e (sonst wie B) E 


\title{
XIII
}

\section{Der einfältige Ritter}

$\mathrm{I} 52 r a$

\author{
I Ez reit ein ritter, der was tump, \\ uf einer straze, diu was chrump. \\ daz schuf ein berch, der da stunt, \\ als noch genuge berge tunt, \\ 5 da man muz riten umbe. \\ do sprach der selbe tumbe: \\ „ditz ist ein erwunschtez burchstal, \\ ez ist ze bereit noch ze smal. \\ zwar, da enist niht wider, \\ Io ezn ist ze hoh noch ze nider; \\ sold ich nach minem willen han, \\ ein burc diu muse druffe stan." \\ er begunde hinuf riten \\ und chom ze der andern siten, \\ I5 diu was bezzer oder als guot. \\ er sprach: „min herce und min muot
}

$A$ 204. $B$ 50. E 29. F 2. $H I_{4}$ O. I 46

Uberschrift in $B I$ : Von dem

chön perg

Uberschrift in E: Von eime ritter

In HI hat der Antang keine

Initialen, aber Platz dafür ist

freigelassen. H hat keine

Uberschrift

U'berschrift in F: Von ainem

buzg[tall

5 Daz man $B E I$

7 Daz ift ain erwelts $B E I$;

Daz ift eín $H$. burchstal -„Stätte für eine Burg”
$8 \mathrm{Ez}$ nicht ze $B$; ift niht ze $E I$; if t wedez zu $F$; Izn ift niht $H$

Io vor $9 B E H I$

9 en fehlt BEHI. Wezlich da ift $F$. zwar - ,Kurzform von zeware". da enist niht wider - ,es gibt nichts Vergleichbares"

ro ezn ist fehlt $B E H I$; Es ift weder zu $F$

I3 hín vmb $B E H I$

I4 sitten $A$

I5 pezzer dann gut $B I$. was fehlt $E$ 
I7 diu heten immer frouden schin, sold ich mit huse daruffe sin." als er die dritten sitten sach,

20 diu was so gut, daz er des jach: "ditze ist diu beste burchstat, da ie dehein man uf getrat." als er zu der vierden sitten cham, do wart er dem berge gram.

25 diu was so ubele gestalt, daz er sich selben darumbe schalt, daz er den berc het gelobet. er sprach: „zewar, ich han getobet, daz ich dir gutes han gejehen:

30 ich han so boses niht gesehen." sus schuf diu virde sitte daz, daz er dem berge wart gehaz.

Als der tumbe ritter warp, des lop so schiere verdarp,

35 also chan noch manger werben. des lop daz muz verderben, der, wenne er siht ein fremde wip und iesa minnet ir lip fur alle, die er hat gesehen

40 und im sin mut beginnet jehen, si ubersuze alle sueze, swie vil ez chosten mueze, er muezze ir minne erwerben ode ane trost verderben

I7 Hetn hoher frawdn $B E I$

I9 [ah an $B I$. Do er $H$

20 gvt al $[$ er iach $H$

20-23 fehlen BI

2 I Daz ift die $H$

23 Do er zer vierden $H$

$24 \operatorname{der} A$; dem perg $B E H I$; büzge $F$. wart er gram „ärgerte er sich über"

$29 \mathrm{v}$ siehen $E F H$

3 I Es [chuef $F$

33 Versalien in $H$
34 [o fer verdarb $B I$

36 Daz \{ein lob muz BEI; lob mues verderben $F H$

37 Swenn er $B E I$. Der fehlt $F$

38 ie a fehlt $F$ (Platz dafür ist freigelassen)

4I v̈br [üzzt $B I$; Sie [ie $\int \stackrel{e}{\mathrm{e} z z e}$ v'ber alle $E$; aller $H$

44 er[terbñ $B E I$

Nach 44 zwei Mehverse in $H$ $44 a$ Vñ wendet fíne fínne $b$ Vil gahez an ír mínne 
45 durch die jugent, die si hat, und daz ir gar ze wunsche stat

$152 r b$ daz antlutze und aller ir lip, und ist vil gar ein schone wip. swie gut die dri siten sint:

50 daz si der jare ist ein chint und wol geschaffen dabi, swie schone si si, ist si ze der vierden siten chranc, daz er ir herce und ir gedanc

55 gar ane tugende vindet, des loben daz verswindet, swenne im ir valsch wirt bechant, sam des ritters lop verswant, der dem berge grozer gute jach

60 und in sit schalt, do er gesach die vierden siten, da die dri gar verderbet waren bi.

45 ir jvgent $H$

5 I wolbe chafenn $F$

52 Vñ wie $B E I$; Vn fwi vil fchone $H$

55 Gar fehlt $F$

56 lob $B I$; lop da $E$; lob da [chier ver [windett $F$
57 ir wal $B$, ezckant $F$. ir wol $I$ 58 [am fehlt $B I$. Wann des $F$ 59 perg wírde jach $B E I$

60 er In fach $B E I$. Vnd feidez [chalt da ez in ge [ach $F$. Iah $H$

62 gar fehlt $F$; Vil gar $H$ 




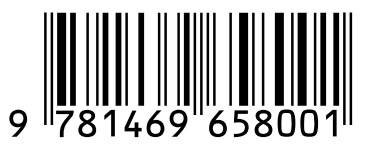

